\title{
Complacency and Bias in Human Use of Automation: An Attentional Integration
}

\author{
Raja Parasuraman, George Mason University, Fairfax, Virginia, and \\ Dietrich H. Manzey, Berlin Institute of Technology, Berlin, Germany
}

Objective: Our aim was to review empirical studies of complacency and bias in human interaction with automated and decision support systems and provide an integrated theoretical model for their explanation.

Background: Automation-related complacency and automation bias have typically been considered separately and independently.

Methods: Studies on complacency and automation bias were analyzed with respect to the cognitive processes involved.

Results: Automation complacency occurs under conditions of multiple-task load, when manual tasks compete with the automated task for the operator's attention. Automation complacency is found in both naive and expert participants and cannot be overcome with simple practice. Automation bias results in making both omission and commission errors when decision aids are imperfect.Automation bias occurs in both naive and expert participants, cannot be prevented by training or instructions, and can affect decision making in individuals as well as in teams. While automation bias has been conceived of as a special case of decision bias, our analysis suggests that it also depends on attentional processes similar to those involved in automation-related complacency.

Conclusion: Complacency and automation bias represent different manifestations of overlapping automationinduced phenomena, with attention playing a central role. An integrated model of complacency and automation bias shows that they result from the dynamic interaction of personal, situational, and automation-related characteristics.

Application: The integrated model and attentional synthesis provides a heuristic framework for further research on complacency and automation bias and design options for mitigating such effects in automated and decision support systems.

Keywords: attention, automation-related complacency, automation bias, decision making, human-computer interaction, trust

Address correspondence to Raja Parasuraman, Arch Lab, MS 3F5, George Mason University, 4400 University Drive, Fairfax, VA 22030; rparasur@gmu.edu.

\section{HUMAN FACTORS}

Vol. 52, No. 3, June 2010, pp. 381-410.

DOI: $10.1177 / 0018720810376055$.

Copyright (C) 2010, Human Factors and Ergonomics Society.

\section{INTRODUCTION}

Human interaction with automated and decision support systems constitutes an important area of inquiry in human factors and ergonomics (Bainbridge, 1983; Lee \& Seppelt, 2009; Mosier, 2002; Parasuraman, 2000; R. Parasuraman, Sheridan, \& Wickens, 2000; Rasmussen, 1986; Sheridan, 2002; Wiener \& Curry, 1980; Woods, 1996). Research has shown that automation does not simply supplant human activity but rather changes it, often in ways unintended and unanticipated by the designers of automation; moreover, instances of misuse and disuse of automation are common (R. Parasuraman \& Riley, 1997). Thus, the benefits anticipated by designers and policy makers when implementing automation - increased efficiency, improved safety, enhanced flexibility of operations, lower operator workload, and so on-may not always be realized and can be offset by human performance costs associated with maladaptive use of poorly designed or inadequately trained-for automation.

In this article, we review research on two such human performance costs: automationrelated complacency and automation bias. These have typically (although not exclusively) been considered in the context of two different paradigms of human-automation interaction, supervisory control (Sheridan \& Verplank, 1978) and decision support, respectively. We discuss the cognitive processes associated with automation complacency and automation bias and provide a synthesis that sees the two phenomena as representing different manifestations of overlapping automation-induced phenomena, with attention playing a central role.

\section{AUTOMATION COMPLACENCY}

\section{Definitions}

The term complacency originated in references in the aviation community to accidents or incidents in which pilots, air traffic controllers, or other 
operators purportedly did not conduct sufficient checks of system state and assumed "all was well" when in fact a dangerous condition was developing that led to the accident. The National Aeronautics and Space Administration Aviation Safety Reporting System (ASRS) includes complacency as a coding item for incident reports (Billings, Lauber, Funkhouser, Lyman, \& Huff, 1976). ASRS defines complacency as "self-satisfaction that may result in nonvigilance based on an unjustified assumption of satisfactory system state" (Billings et al., 1976, p. 23). Wiener (1981) discussed the ASRS definition as well as several others, including complacency defined as "a psychological state characterized by a low index of suspicion" ( $p$. 119). Wiener proposed that empirical research was necessary to go beyond these somewhat vague definitions so as to gain an understanding of the mechanisms of complacency and to make the concept useful in enhancing aviation safety.

Currently, there is no consensus on the definition of complacency. However, there is a core set of features among many of the definitions that is common both to accident analyses and to empirical human performance studies that could be used to derive a working definition. The first is that human operator monitoring of an automated system is involved. The second is that the frequency of such monitoring is lower than some standard or optimal value (see also Moray $\&$ Inagaki, 2000). The third is that as a result of substandard monitoring, there is some directly observable effect on system performance. The performance consequence is usually that a system malfunction, anomalous condition, or outright failure is missed (R. Parasuraman, Molloy, $\&$ Singh, 1993). Technically, the performance consequence could also involve not an omission error but an extremely delayed reaction. However, in many contexts in which there is strong time pressure to respond quickly, as in an air traffic control(ATC) conflict detection situation (Metzger $\&$ Parasuraman, 2001), a delayed response would be equivalent to a miss.

\section{Accident and Incident Reports}

Operator complacency has long been implicated as a major contributing factor in aviation accidents (Hurst \& Hurst, 1982). Wiener (1981) reported that in a survey of 100 highly experienced airline captains, more than half stated that complacency was a leading factor in accidents. Initially, complacency was used to refer to inadequate pilot monitoring in relation to any aircraft subsystem. With the advent of automation, however, first in the aviation industry and later in many other domains, the possibility arose of automation-related complacency. Consistent with this trend, in a more recent analysis of aviation accidents involving automated aircraft, Funk et al. (1999) also reported that complacency was among the top five contributing factors.

Complacency has also been cited as a contributing factor in accidents in domains other than aviation. A widely cited example is the grounding of the cruise ship Royal Majesty off the coast of Nantucket, Massachusetts (Degani, 2001; R. Parasuraman \& Riley, 1997). This ship was fitted with an automatic radar plotting aid (ARPA) for navigation that was based on GPS receiver output. The GPS receiver was connected to an antenna mounted in an area where there was heavy foot traffic of the ship's crew. As a result, the cable from the antenna frayed, leading to a loss of the GPS signal. At this point, the ARPA system reverted to "dead reckoning" mode and did not correct for the prevailing tides and winds. Consequently, the ship was gradually steered toward a sand bank in shallow waters. The National Transportation Safety Board (1997) report on the incident cited crew overreliance on the ARPA system and complacency associated with insufficient monitoring of other sources of navigational information, such as the Loran $\mathrm{C}$ radar and visual lookout.

Automation complacency has been similarly cited in several other analyses of accidents and incidents (Casey, 1998). The dangers of complacency have been described in many commentaries and editorial columns, including those in leading scientific journals, such as Science (e.g., Koshland, 1989). Perhaps as a result of reading such anecdotal reports and opinion pieces (which have a tendency to overgeneralize and draw very broad conclusions), Dekker and colleagues (Dekker \& Hollnagel, 2004; Dekker \& Woods, 2002) proposed that terms such as complacency and situation awareness do not have scientific credibility but rather are simply "folk 
models." R. Parasuraman, Sheridan, and Wickens (2008) disputed this view, pointing to the growing scientific, empirical literature on the characteristics of both constructs.

Accident and incident reports clearly cannot be held to high scientific standards, but they provide a useful starting point for scientific understanding of any phenomenon. Describing the characteristics of complacency through empirical research would therefore appear to be an important goal. In the three decades since the early anecdotal reports and accident analyses mentioning complacency, a number of investigators have followed Wiener's (1981) call for such empirical research.

\section{Early Empirical Evidence for Complacency Effects in Monitoring Automated Systems}

Thackray and Touchstone (1989) conducted an early yet ultimately unsuccessful attempt to obtain evidence of complacency. They had participants perform a simple ATC task requiring detection of aircraft-to-aircraft conflicts (e.g., those within 5 nautical miles of each other) with or without a simulated automation aid that indicated that a conflict would occur. The automation failed twice, once early and once late during a 2-hr session. Although observers were somewhat slower to respond to the first failure when using the automation, this was not the case for the later failure. Moreover, participants were as accurate at monitoring for conflicts with automation as they were when performing the task manually, if not more so.

Thackray and Touchstone (1989) indicated that their failure to obtain reliable evidence of complacency might be related to their use of a relatively short test session, even though their testing period was $2 \mathrm{hr}$ long and their ATC task was so simple and monotonous that many participants experienced considerable boredom (Thackray, 1981). However, subsequent studies in which complacency effects have been found in shorter periods and with more complex tasks indicate that the short test duration was unlikely to have been the major reason for their failure. A more likely factor is the extremely simple nature of the assignment given to the participants in their study, who, unlike controllers conducting real ATC operations, did not have any competing tasks, only conflict detection.

R. Parasuraman et al. (1993) provided the first empirical evidence for automation complacency and for the contributing role of high task load. They had participants perform three concurrent tasks from the Multiple Task Battery (MATB): a two-dimensional compensatory tracking and an engine fuel management task, both of which had to be carried out manually, and a third task involving engine monitoring that required participants to detect abnormal readings on one of four gauges; this task was supported by an automated system that was not perfectly reliable. In different conditions, the automation had either high $(88 \%)$ or low $(52 \%)$ reliability in detecting engine malfunctions. Complacency was operationally defined as the operator's not detecting or being slow to detect failures of the automation to detect engine malfunctions.

The variability of automation performance over time was also manipulated on the basis of Langer's (1989) concept of "premature cognitive commitment," defined as an attitude that develops when a person first encounters a device in a particular context and that is then reinforced when the device is reencountered in the same way. Langer (1982) proposed that repeated exposure to the same experience leads people to engage in "automated" or "mindless" behavior. R. Parasuraman and colleagues (1993) therefore reasoned that automation that is unchanging in its reliability is more likely to induce complacency than is automation that varies. In this case, participants will be more likely to develop a premature cognitive commitment regarding the nature of the automation and its efficiency. On the other hand, participants encountering inconsistent automation reliability should have a more open attitude concerning the efficiency of the automation and hence should be less likely to be complacent. Finally, to examine the effects of multiple-task load, Parasuraman et al. also conducted a second experiment in which participants had to perform only the engine-monitoring task with automation support under either the constant-reliability or the variable-reliability condition. 


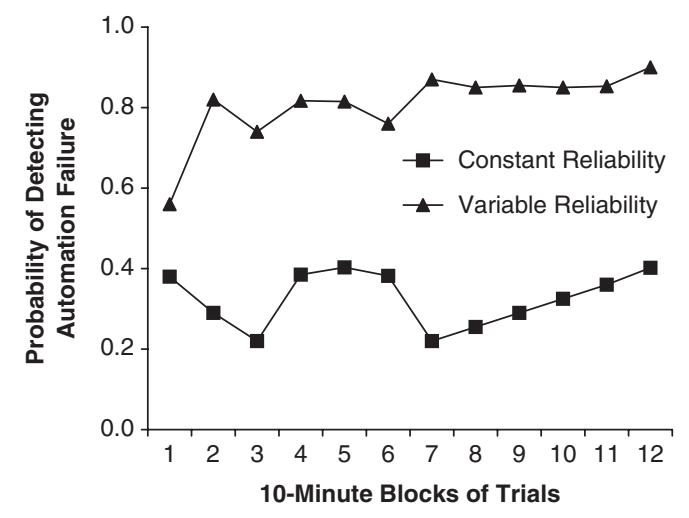

Figure 1. Detection of automation failures under constant-reliability and variable-reliability conditions. Adapted from "Performance Consequences of Automation-Induced 'Complacency," by R. Parasuraman, R. Molloy, and I. L. Singh, 1993, International Journal of Aviation Psychology, 3, p. 10. Copyright 1993 by Taylor and Francis. Adapted with permission.

The results showed that complacency effects were linked both to the consistency of automation reliability and to task load. The mean detection rate of automation failures was markedly higher for the variable-reliability condition (82\%) than for the constant-reliability condition $(33 \%)$ (see Figure 1). The magnitude of the effect-a $149 \%$ difference in detection rate - is dramatic, considering that under single-task conditions, detection of engine malfunctions was quite easy, averaging about $97 \%$.

R. Parasuraman et al. (1993) also found that detection of automation failures was significantly poorer in the multitask condition than in the single-task condition. When participants had simply to "back up" the automation routine without other duties, monitoring was efficient and near perfect in accuracy $(\sim 100 \%)$.

These results indicate that automationinduced complacency is more easily detectable in a multitask environment when operators are responsible for many functions and their attention is focused on their manual tasks. Importantly, the findings suggest that complacency is not a passive state that the operator falls into (as the usage in everyday parlance would suggest). Rather, automation complacency represents an active reallocation of attention away from the automation to other manual tasks in cases of high workload.

\section{Factors Influencing Automation Complacency}

There have been a number of additional studies examining the characteristics of automation complacency following the original study by R. Parasuraman et al. (1993). One question is whether the spatial location of the automated task is an important factor in automation complacency. In the Parasuraman et al. study, the automated task was always presented in the periphery, away from the primary manual tasks that were centrally displayed. It is possible that the peripheral location led participants to neglect the automated task. Singh, Molloy, and Parasuraman (1997) accordingly examined whether centrally locating the automated engine-monitoring task would boost performance and reduce or eliminate the complacency effect. They had participants perform the same three tasks and the same conditions as in Parasuraman et al., with the single change that the engine-monitoring task was moved to the center of the display, with the tracking and fuel management tasks located below it. Singh et al. found that monitoring for automation failure was inefficient when automation reliability was constant but not when it varied over time, replicating Parasuraman et al. Thus, the automation complacency effect was not prevented by centrally locating the automated task.

Automation reliability. In the automation complacency studies described thus far, the automation failure rate was relatively high, for example, $12 \%$ in the "high" reliability condition of R. Parasuraman et al. (1993). Such high (and even higher) values of failure rate were needed for the study so that a sufficient number of data points could be generated for estimating the detection performance of individual participants on the engine-monitoring task. But an obvious drawback is that such high failure rates are unrepresentative of any real automated system or at least any system that human operators would use.

To address this criticism, Molloy and Parasuraman (1996) conducted a study in which the automation failed on only a single occasion 
during a test session. Participants performed the same MATB simulation as in the R. Parasuraman et al. (1993) study. Two groups of participants performed the MATB under either a multitask or a single-task condition, and a third group performed a simple line discrimination task; within each group, participants performed two 30-min sessions separated by a rest break. For the two groups performing the MATB, the automation failed only once in each session, either early (first $10 \mathrm{~min}$ ) or late (last $10 \mathrm{~min}$ ); for the group given the simple vigilance task, only one signal was presented, either early or late in the $30-\mathrm{min}$ session.

The authors found that in the single-task MATB condition, most participants detected the automation failure, whether it occurred early or late. Under multitask conditions, however, only about half the participants detected the automation failure, and an even smaller proportion detected the failure if it occurred late than if it occurred early (see Figure 2). Bailey and Scerbo (2007) replicated this finding using a somewhat different multitask flight simulation based on the MATB.

De Waard, van der Hulst, Hoedemaeker, and Brookhuis (1999) provided additional confirmatory evidence in a study of automation in driving. They had participants in a simulator drive a vehicle fitted for operation in an automatic highway system (AHS), in which steering and lateral control were automated but could be overridden by depressing the brake. Toward the end of the scenario and on a single occasion, a vehicle merged suddenly into the same lane in front of the participant's AHS vehicle. The AHS failed to detect the intrusion (automation failure). De Waard and colleagues found that half of the drivers did not detect the failure, depress the brake, and retake manual control, and 14\% did not respond quickly enough to avoid a collision.

These findings provide additional evidence for the view that automation complacency occurs for highly reliable systems in which automated control fails on only a single occasion. One could argue that even the single failure during a 30 -min session is not representative of real systems, in which even lower failure rates might be seen. For example, in a review of

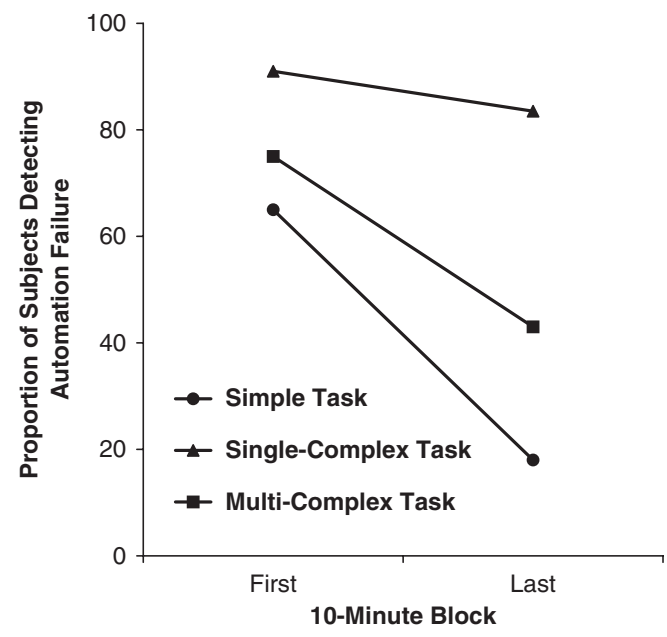

Figure 2. Automation complacency effect for a single automation failure. Adapted from "Monitoring an Automated System for a Single Failure: Vigilance and Task Complexity Effects," by R. Molloy and R. Parasuraman, 1996, Human Factors, 38, p. 318. Copyright 1996 by the Human Factors and Ergonomics Society. Adapted with permission.

various industrial monitoring and inspection jobs, Craig (1984) estimated that a critical signal might occur about once every 2 weeks. However, given the impracticality of empirically testing participants in a laboratory setting with such low signal rates, and given that detection of an unexpected event typically decreases with reductions in signal probability (Davies \& Parasuraman, 1982), these findings indicate that monitoring for automation failures is likely to be even poorer for very low failure rates representative of real but imperfect automated systems.

These considerations also suggest that decreases in automation reliability should reduce automation complacency, that is, increase the detection rate of automation failures. In the R. Parasuraman et al. (1993) study, two automation reliability levels were compared, low and high, and although participants detected more automation failures at the low reliability, the difference was not statistically significant, possibly because of low power. In a replication study, however, Bagheri and Jamieson (2004) did find that participants detected significantly more automation failures at low than at high automation reliability. Moreover, they confirmed 
Parasuraman et al.'s finding that detection performance was better under variable-reliability than under constant-reliability automation. Finally, May, Molloy, and Parasuraman (1993) varied automation reliability across a range of values under the same multitask condition used in Parasuraman et al. They found that the detection rate of automation failures varied inversely with automation reliability, but no evidence was found for a lower limit of automation reliability below which automation complacency did not occur. Rather, detection of automation failures was still worse than manual performance even at a low level of automation reliability.

Complacency represents a cost that can offset the benefits that automation can provide. One would presume that when the reliability level of an automated system falls below some limit, that there would be neither benefits nor costs associated with automation. Wickens and Dixon (2007) proposed that this cutoff value is approximately $70 \%$ (with a standard error of $\pm 14 \%$ ), on the basis of studies examining the beneficial effects of automation support. If this objective standard was followed, then observers should not rely on imperfect automation whose reliability falls below this value, but Wickens and Dixon reported that some continue to do so. Congruent with this finding, May et al. (1993) also found that participants continued to show complacency effects even at low automation reliability. Moreover, other researchers have found that even automation with reliabilities lower than the $70 \%$ cutoff value can support human operators who also have access to the "raw" information sources, which they can combine with the automation output to improve overall performance (de Visser \& Parasuraman, 2007; St. John, Smallman, Manes, Feher, \& Morrison, 2005).

Automation reliance appears to be strongly context dependent, with the $70 \%$ threshold being important primarily under high workload (Wickens \& Dixon, 2007). Multiple-task conditions are also where the automation complacency effect is strongest. Whether there is a fixed lower bound of automation reliability, below which neither benefits nor costs accrue, and the influence of contextual factors on such a threshold are issues that need further investigation.
First-failure effect. In addition to the overall automation failure rate, the temporal sequence of failures and the time between failures may be important factors to consider as well. If complacency reflects an operator's initial attitude toward high-reliability automation based on high trust, then a failure to monitor is perhaps to be expected the first time the automation fails. Lee and Moray $(1992,1994)$ showed that the reduction in operator trust following an automation failure was followed by a recovery in trust but at a slow rate. If so, then one would expect the complacency effect to be high for the first failure but to dissipate thereafter, a phenomenon Merlo, Wickens, and Yeh (2000) referred to as the first-failure effect. Some evidence for the effect was reported in a recent study by Rovira, McGarry, and Parasuraman (2007) in which participants had to make simulated battlefield engagement decisions under time pressure with the aid of imperfect automation. Performance declined the first time automation failed but improved on subsequent failures.

These findings suggest that complacency is associated with a cognitive orientation toward very-high-reliability automation prior to the first time it has failed in the user's experience (R. Parasuraman \& Wickens, 2008). Subsequent exposure to automation failures may allow for better calibration to the true reliability, so that detection performance improves. However, whereas Rovira et al. (2007) did find some corroborative evidence, other studies using different tasks have not found consistent evidence for the first-failure effect (Wickens, Gempler, \& Morphew, 2000).

Expertise and automation realism. Although the evidence for the first-failure effect is equivocal, the phenomenon raises the issue of whether complacency-like effects stem from insufficient experience with the automation or from inadequate practice in performing the automated task. With respect to the first issue, it is noteworthy that the complacency studies described thus far all involved artificial types of automation not found in real systems. Furthermore, college students were used as participants. What of experienced, skilled workers who are tested with automation more closely resembling real automated systems? Do they exhibit automation 
complacency? Three studies have provided a positive answer to this question.

First, using the MATB simulation, Singh, Molloy, Mouloua, Deaton, and Parasuraman (1998) compared the performance of pilots with an average of approximately $440 \mathrm{hr}$ of flight experience with that of nonpilots in the same paradigm developed by R. Parasuraman et al. (1993). Clear complacency effects were obtained for both groups, although the pilots detected more automation failures than did the nonpilots.

Second, Galster and Parasuraman (2001) tested general aviation pilots with several hundred hours of flight experience on a multitask flight simulation involving Instrument Flight Rated flight using an actual cockpit automation system, the Engine Indicator and Crew Alerting System (EICAS). Clear evidence of a complacency effect was found, with pilots detecting fewer engine malfunctions when using the EICAS than when performing this task manually.

In a third study, by Metzger and Parasuraman (2005), experienced air traffic controllers were tested on a high-fidelity simulation of a future ATC (Free Flight) scenario requiring detection of conflicts among "self-separating" aircraft. Controllers were supported by a "conflict probe" automation that pointed to a potential conflict several minutes before its occurrence. The automation failed once toward the end of the scenario. The authors found that significantly fewer controllers detected the conflict when the conflict probe failed than when the same conflict was handled manually. This result was consistent with an earlier finding from this group showing that conflict detection performance was better when controllers were actively involved in conflict monitoring and conflict resolution ("active control") than when they were asked to be passive monitors in a simulated Free Flight scenario involving pilot self-separation (Galster, Duley, Masalonis, \& Parasuraman, 2001; Metzger \& Parasuraman, 2001).

Training. Notwithstanding these findings with expert pilots and controllers, another aspect of experience is familiarity with the simulation, automation, and task setting per se. Could the complacency effect simply reflect insufficient practice at performing the automated task in conjunction with other manual tasks? Singh,
Sharma, and Parasuraman (2001) found that the automation complacency effect obtained in the standard paradigm described by R. Parasuraman et al. (1993) was not reduced by up to $60 \mathrm{~min}$ of training.

Although extended practice does not eliminate automation complacency, other training procedures may provide some benefit. In particular, given that complacency is primarily found in multitasking environments and represents attention allocation away from the automated task, training in attention strategies might mitigate complacency.

One such training procedure is the variablepriority method proposed by Gopher (1996; Gopher, Weil, \& Siegel, 1989). For example, in a dual-task setting, observers are trained to devote greater priority to one task (say, $80 \%$ ) and less to the other (20\%) in one block of training trials, followed by the reverse priority in a subsequent block. Compared with fixed, equalpriority training (50\% and 50\%), variable-priority training results in faster acquisition of dualtask skills. Accordingly, Metzger, Duley, Abbas, and Parasuraman (2000) trained participants in the three subtasks of the MATB using either the variable- or the fixed-priority method and examined both overall performance and detection of failures in the automated task (complacency). Variable-priority training led to better multitasking performance, and a trend for a reduction in the automation complacency effect was observed. An additional training method that might reduce complacency includes experience of automation failures (Bahner, Huper, \& Manzey, 2008). We consider this method in a later section of this article, where studies of automation bias are discussed.

\section{Automation Complacency, Attention, and Trust}

The studies discussed thus far have shown that automation complacency-operationally defined as poorer detection of system malfunctions under automation control compared with manual control-is typically found under conditions of multiple-task load, when manual tasks compete with the automated task for the operator's attention. The operator's attention allocation strategy appears to favor his or her manual 
tasks as opposed to the automated task. This strategy may itself stem from an initial orientation of trust in the automation, which is then reinforced when the automation performs at the same, constant level of reliability.

The finding that variable-reliability automation, fluctuating between high and low and back again, is associated with the elimination of complacency is certainly compatible with the notion that reduced operator monitoring of the automation could be linked to trust. Thus, as Moray (2003; Moray \& Inagaki, 2000) pointed out, an attention strategy devoted primarily to manual tasks and only occasionally to the automated task can be considered rational (see also Sheridan, 2002). Moray (2003; Moray \& Inagaki, 2000) also suggested that complacency could be inferred only if the operator's rate of sampling of the automated task was below that of an optimal or normative observer. Moray's views are considered further later in this article, but for now, we simply note that these considerations reinforce a close link between automation complacency, attention, and trust. Figure 3 shows a schematic of these links. The operator uses an attention allocation strategy to sample his or her manual tasks, with attention to the automated task being driven in part by trust.

The original R. Parasuraman et al. (1993) study also discussed the finding of automated complacency under constant-reliability conditions in terms of attentional and trust factors. However, that study did not obtain independent measures either of attention or of trust. Subsequent studies have used eye movement recordings to examine attention allocation under conditions of manual and automation control. In particular, Metzger and Parasuraman (2005) used different measures of eye movements to examine the attentional theory of automation complacency.

In this study, experienced air traffic controllers were required to detect aircraft-to-aircraft conflicts either manually or with the aid of automation (a "look-ahead" conflict probe). Toward the end of the scenario, the automation failed on a single occasion. A greater proportion of controllers missed detecting the conflict with the automation than when, in a separate session, they handled the same conflict (rotated in sector geometry to reduce familiarity effects) without the help of automation. Among controllers who

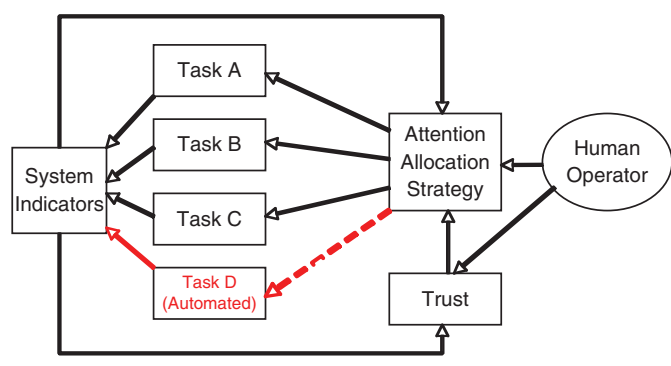

Figure 3. Attention allocation and trust in manual and automated tasks.

detected the conflict in both the automation and the manual conditions, there were no differences in the number of fixations of the primary radar display where the conflicting aircraft were shown. Among controllers who missed the conflict, however, there were significantly fewer fixations of the radar display under automation support than under manual control. This finding provides strong evidence for a link between the automation complacency effect and reduced visual attention to the primary information sources feeding automation which must be monitored to detect an abnormal event (for related eye movement evidence on complacency, see Baghieri \& Jamieson, 2004, and Wickens, Dixon, Goh, \& Hammer, 2005).

Although these studies point to a role for attention allocation in the automation complacency effect, their interpretation depends on the assumption of a close link between eye movements and attention. There is considerable evidence for a link between the two (Corbetta, 1998; Shepherd, Findlay, \& Hockey, 1986), and studies of covert shifts of attention show that such attention shifts typically precede an eye movement (Hoffman \& Subramaniam, 1995). However, attention and eye movements can also be dissociated, and the phenomena of "inattentional blindness" or "change blindness" (Mack \& Rock, 1998; Simons \& Rensink, 2005) indicates that relatively salient items of information in the environment can be missed even if they are fixated (R. Parasuraman, Cosenzo, \& de Visser, 2009; Thomas \& Wickens, 2006). Thus, although an eye fixation generally indicates that a location was attended, it need not always do so, because attention may have moved to another location - the so-called looking-butnot-seeing phenomenon. 
Duley, Westerman, Molloy, and Parasuraman (1997) reexamined the automation complacency effect to see whether it could be reduced or eliminated by forcing eye fixations on the automated task. They did this by superimposing the (automated) engine-monitoring task on the manual tracking task in the MATB simulation, carefully interleaving the display elements of each task so that they did not mask each other. They chose the tracking task for superimposition because it was a high-bandwidth task (cf. Moray \& Inagaki, 2000) that needed to be frequently visually sampled for successful performance. Thus, operators would repeatedly have to fixate the tracking task, and by doing so, the automated task would also fall within foveal vision at the same time. Surprisingly, Duley et al. found that the standard complacency effect of R. Parasuraman et al. (1993) was again found: Participants were poorer in detecting engine malfunctions under automation than when they did the task manually. Tracking performance was equally good under both conditions. Thus, the automation complacency effect could not be attributed to insufficient sampling of the automated task. These findings suggest that attention allocation away from the automated task associated with complacency may include not only fixation failures but attention failures as well.

In addition to visual attention, automation complacency has been linked to an initial attitude of high trust toward the automation. Trust was not directly measured in the original R. Parasuraman et al. (1993) study. However, subjective measures of trust were obtained in two subsequent studies, by Baghieri and Jamieson (2004) and by Bailey and Scerbo (2007). Consistent with Parasuraman et al., Baghieri and Jamieson found that constant-reliability automation led to poorer detection of automation failures than did variable-reliability automation, but this effect was not associated with higher subjective trust. However, in two experiments conducted by Bailey and Scerbo using the single-failure paradigm of Molloy and Parasuraman (2006), an inverse relationship was observed between subjective trust (measured with a 12-item questionnaire) and monitoring performance, although the relationship emerged only when data from the two separate experiments were combined. In a review of trust and automation studies, Lee and See (2004) did not find convincing links between poor automation monitoring and high trust in automation, and currently, the Bailey and Scerbo study provides the only, somewhat tentative, evidence.

One reason for the weak evidence for a relationship between complacency and trust is the potential discrepancy between subjective and objective measures of trust. Overt behavioral indicators of trust, as revealed, for example, in verification activities (St. John et al., 2005), may provide stronger evidence of a closer link. We consider this issue further later, when we discuss a study by Bahner et al. (2008).

\section{Individual Differences}

There are considerable individual differences in the performance effects associated with automation complacency. R. Parasuraman et al. (1993) found that in the experimental group that exhibited this effect, the mean detection rate of automation failures was quite low, 33\%. But there was considerable variability around this mean, and as many as half of the participants in the group did not detect any malfunctions ( $0 \%$ detection) on one of the blocks of the test session. Clearly, some participants exhibit the effect to a greater extent than others. What is the source of these individual differences?

In an initial examination of individual differences, Singh, Molloy, and Parasuraman (1993a) distinguished between complacency potential and behavior. Although an attitude of trust toward automation can foster overreliance, this may not in itself lead to complacent behavior but may indicate only a potential for complacency. Complacent behavior-as reflected in poor monitoring of automation-may occur only when complacency potential coexists with other conditions, such as high task load. Individuals may differ both in the potential they "bring" to a task setting as well as in their response to that setting.

Singh et al. (1993a) developed a 20-item scale, the Complacency Potential Rating Scale (CPRS), with items covering attitudes toward commonly encountered automated devices (such as automatic teller machines). Factor analysis of questionnaire responses in a psychology college population and a different sample of 
engineering students (R. Parasuraman, Singh, Molloy, \& Parasuraman, 1992) revealed factors with good internal consistency and test-retest reliability, suggesting that the CPRS might be useful in validation studies examining individual differences in complacent behavior.

Singh, Molloy, and Parasuraman (1993b) reported one such study. They administered the CPRS to two groups of participants who performed the MATB simulation in the same conditions of the R. Parasuraman et al. (1993) study. There was some evidence that complacent behaviorpoor detection of automation failures - was associated $(r=-.42)$ with higher complacency potential as measured by the CPRS. However, this correlation emerged only when the participants were subdivided by a median split of CPRS scores into low- and high-complacency-potential groups, with the association being found only for high-complacency-potential participants. Singh et al. suggested that there is perhaps a threshold of complacency potential, with a link between general attitudes of reliance and trust toward automation being reflected in complacent performance only in individuals who exhibit such attitudes to a strong degree. Very similar findings were reported in a replication study by Prinzel, DeVries, Freeman, and Mikulka (2001), who found that individuals scoring high on the CPRS were particularly poor in monitoring automation under constantthan under variable-reliability automation.

Singh et al. (1993a) proposed that complacency potential represents an attitude toward automation rather than an enduring trait. Consistent with this view, Singh et al. (1993b) found no relationship between the automation complacency effect and the personality trait of extraversion-introversion. Prinzel et al. (2001) also found no association with measures of boredom proneness or absentmindedness, although in a subsequent study, they did find some evidence for a negative correlation between automation complacency and selfefficacy (Prinzel, 2002). In general, however, strong associations between personality or related indices of personal variability and automation complacency have not been found. However, the currently available database is very small and therefore does not warrant any decisive conclusions.
With respect to other sources of individual or group differences, there do not appear to be any gender differences in complacency. However, adult age differences in automation complacency have been reported, with older adults exhibiting greater automation-related complacency but only under very high workload conditions (Hardy, Mouloua, Dwivedi, \& Parasuraman, 1995; Vincenzi, Muldoon, Mouloua, Parasuraman, \& Molloy, 1996).

\section{Summary}

The studies discussed thus far have shown that automation complacency-operationally defined as poorer detection of system malfunctions under automation compared with under manual control-is typically found under conditions of multiple-task load, when manual tasks compete with the automated task for the operator's attention. Several factors modulate this effect: It is largely eliminated when automation reliability is varied over time as opposed to when reliability remains constant. Automation complacency is also reduced when the automation failure rate is increased, but the issue of whether there is a threshold reliability level below which automation complacency does not occur remains unresolved. Conversely, complacency occurs for highly reliable (yet imperfect) automation and even when the automation fails on only a single occasion in the operator's experience.

Finally, experience and practice do not appear to mitigate automation complacency: Skilled pilots and controllers exhibit the effect, and additional task practice in naive operators does not eliminate complacency. It is possible that specific experience in automation failures may reduce the extent of the effect. Automation complacency can be understood in terms of an attention allocation strategy whereby the operator's manual tasks are attended to at the expense of the automated task, a strategy that may be driven by initial high trust in the automation.

\section{AUTOMATION BIAS}

\section{Automated Decision Aids}

Automated decision aids are devices that support human decision making in complex environments. A dichotomous alarm system that alerts human operators to a potential hazard 
represents the most basic example (Wiegmann, 2002). More complex examples include the Traffic Conflict and Alert System (TCAS) and the Ground Proximity Warning System (GPWS), which are installed in many commercial aircraft. Other examples include navigation aids in cars, fault diagnosis and management systems in process control, and expert systems for physicians or computer-based aids for surgeons in the medical domain.

Such systems are meant to support human cognitive processes of information analysis and/or response selection by providing automatically generated cues to help the human user correctly assess a given situation or system state and to respond appropriately. Two different functions of decision aids can be distinguished: alerts and recommendations. The alert function, which is the main feature of simple alarm systems and is embedded in more complex decision aids, makes the user aware of a situational change that might require action. In a car navigation aid, for example, this function is activated whenever a turn must be made. The recommendation function involves advice on choice and action. For example, navigation aids provide specific recommendations of where to drive; cockpit warning systems, such as TCAS or GPWS, provide pilots with specific commands (e.g., "Pull up! Pull up!") to avoid collision; and medical expert systems provide recommendations about appropriate treatment of patients and choice of drug doses.

\section{Definition and Characteristics of Automation Bias}

Automated decision aids are meant to enhance human decision-making efficiency. This is of particular value in areas where incorrect decisions have high costs in terms of either economic consequences (e.g., in the area of manufacturing) or safety outcomes (e.g., aviation, medicine, process control). If the benefit of a decision aid is to be realized, it needs to be used appropriately. Quite often, however, decision aids are misused, for two main reasons. First, the automatically generated cues are very salient and draw the user's attention. Second, users have a tendency to ascribe greater power and authority to automated aids than to other sources of advice.
Consequently, Mosier and Skitka (1996) defined automation bias as resulting from people's using the outcome of the decision aid "as a heuristic replacement for vigilant information seeking and processing" (p. 205). Such a definition treats automation bias as similar to other biases and heuristics in human decision making (e.g., confirmation bias), with the qualification that the bias stems specifically from interaction with an automated system.

Automation bias eventually can lead to decisions that are not based on a thorough analysis of all available information but that are strongly biased by the automatically generated advice. Whereas automation bias is inconsequential when the recommendations are correct, it can compromise performance considerably in case of automation failures, that is, if the aid does not alert the user to become active or if the aid provides a false recommendation or directive. An error of omission, whereby the user does not respond to a critical situation, is related to the alert function. An example from everyday experience is a driver who misses the correct exit from a highway because the navigation aid failed to notify the driver. The second type of error is a commission error, which is related to the specific recommendations or directives provided by an aid. In this case, users follow the advice of the aid even though it is incorrect. An example is a driver who falsely enters a one-way street from the wrong side because the navigation aid (which may not have had the one-way information in its database) tells the driver to do so. Another example is following the advice of an expert flight planner although its recommendations are wrong or less than optimal for a particular situation (e.g., Layton, Smith, \& McCoy, 1994).

Three main factors have been assumed to contribute to the occurrence of automation bias (Dzindolet, Beck, Pierce, \& Dawe, 2001; Mosier \& Skitka, 1996). One is the tendency of humans to choose the road of least cognitive effort in decision making, the so-called cognitive-miser hypothesis (Wickens \& Hollands, 2000). Instead of basing complex decisions on a comprehensive analysis of available information, humans often use simpler heuristics and decision rules (Gigerenzer \& Todd, 1999; 
Kahneman, Slovic, \& Tversky, 1982). Wellknown examples of this tendency include the heuristics of representativeness and availability (Tversky \& Kahneman, 1974). It has been argued that recommendations and directives of automated aids might serve as a strong decision-making heuristic used by the human user as a replacement for more effortful processes of information analysis and evaluation (Mosier \& Skitka, 1996).

A second factor is the perceived trust of humans in automated aids as powerful agents with superior analysis capability (Lee \& See, 2004). As a consequence, users might tend to overestimate the performance of automated aids. More specifically, they may ascribe to the aid greater performance and authority than to other humans or themselves. Some evidence for this effect was provided by Dzindolet, Pierce, Beck, and Dawe (2002). In this study, participants had to predict the performance of an automated aid compared with the expected performance of another human supporting them in a decisionmaking task. It turned out that the majority of participants initially expected the automated aid to perform considerably better than a human aid.

A third contributing factor to automation bias is the phenomenon of diffusion of responsibility. Sharing monitoring and decision-making tasks with an automated aid may lead to the same psychological effects that occur when humans share tasks with other humans, whereby "social loafing" can occur-reflected in the tendency of humans to reduce their own effort when working redundantly within a group than when they work individually on a given task (Karau \& Williams, 1993). Similar effects occur when two operators share the responsibility for a monitoring task with automation (Domeinski, Wagner, Schoebel, \& Manzey, 2007). To the extent that human users perceive an automated aid as another team member, they may perceive themselves as less responsible for the outcome and, as a consequence, reduce their own effort in monitoring and analyzing other available information.

\section{Evidence for Automation Bias}

Aviation studies. Several studies examining pilot interaction with expert systems or with advanced cockpit automation have provided empirical evidence for automation bias (Layton et al., 1994; McGuirl \& Sarter, 2006; Mosier, Palmer \& Degani, 1992; Mosier, Skitka, Heers, \& Burdick, 1998; Sarter \& Schroeder, 2001). Layton et al. (1994) compared the impact of electronic flight planning tools on the quality of the en route flight planning decisions of pilots. The aids differed in their level of automation (LOA): The low LOA left most of the planning decisions to the pilots and provided only an evaluation of different plans, whereas the high LOA specified and recommended a plan. Pilots working with the high LOA aid spent less time and effort in generating and evaluating alternative plans than the group working with the lowLOA aid. This result is consistent with the cognitive-miser hypothesis of automation bias. In addition, a majority of these pilots also tended to accept the plan provided by the automation in cases in which the plan for a number of reasons actually represented a suboptimal solution.

Mosier et al. (1992) studied pilot decision making in simulated engine fire situations, in particular when a decision aid provided wrong advice. An automated electronic checklist was implemented that recommended that the pilot shut down the wrong engine (i.e., the one not affected by fire). Mosier and colleagues found that $75 \%$ of pilots followed the wrong recommendation and neglected to check relevant information available from other indicators. In contrast, only $25 \%$ of pilots using a traditional paper checklist committed the same type of commission error.

In another study, Mosier et al. (1998) had experienced commercial pilots perform a simulated flight in a trainer equipped with advanced cockpit automation systems (e.g., Flight Management System, EICAS). During the simulated flight, various automation failures occurred; each provided opportunities to commit either omission or commission errors. Examples of the first kind included an altitude clearance that did not get loaded correctly, a heading change that was not executed properly by the flight system, and a frequency change misload. In addition, one opportunity for a commission error was presented in the form of a falsely released engine fire warning that occurred without being supported by any other readings of engine parameters or indications available 
from relevant cockpit displays, gauges, and indicators. Although all of these automation failures were, in principle, easily detectable by monitoring the relevant information available from different cockpit displays (e.g., the primary flight display,), the omission error rate was considerable and reached $55 \%$.

The results for the commission error event were even more dramatic: All the pilots decided to shut down the engine in response to the false EICAS alert. This action corresponds to a $100 \%$ commission error rate. This result was in contrast to the indication by the same pilots in a debriefing interview that an EICAS message alone would not be sufficient to shut down an engine completely and that it would be safer under these circumstances to just reduce the power to idle. Clearly, the automatically generated warning must have led the pilots to either ignore (or discount) the contradicting information available from other displays and engine indicators or to believe that it would be in line with the warning, as in a confirmation bias effect. The debriefing interview with the participants provided confirmatory evidence for the latter explanation: $67 \%$ of the pilots reported that they had seen at least one more indication supporting the fire warning from the EICAS (which in fact was absent), an effect termed "phantom memory" by Mosier et al. (1998).

Additional evidence for automation bias was provided in a laboratory experiment comparing the performance of nonpilots in a low-fidelity flight simulation task with and without automation support, the Workload/Performance Simulation (W/PANES; Skitka, Mosier \& Burdick, 1999). Participants had to perform three tasks simultaneously, including a compensatory tracking task, a waypoint task, and a gauge-monitoring task. Both of these latter tasks had to be performed either manually or with the support of an automated aid. During the experiment, automation failures occurred, six in which the automation failed to prompt the participants of a critical event and another six in which it gave a wrong directive. Only 59\% of the former were correctly identified and responded to by the participants, which corresponds to a $41 \%$ omission error rate. In contrast, almost $97 \%$ of participants working without automation detected them correctly.
A similar result emerged for commission errors. In cases in which the automated aid provided a wrong recommendation, approximately $65 \%$ of the participants committed a commission error by following this advice without taking into account the clearly disconfirming evidence directly available from the relevant gauges. All of these effects emerged although the participants were informed that all readings from indicators and gauges were always perfectly valid and provided a reliable basis for cross-checking the automation.

Sarter and Schroeder (2001; see also McGuirl $\&$ Sarter, 2006) examined the performance of pilots interacting with automated decision aids that supported decision making in case of inflight icing events. Such events represent a serious threat to flight safety and must be handled promptly. Consequently, an in-flight icing event is characterized by time pressure and uncertainty: Pilots need to respond rapidly without always being able to verify directly whether icing in fact has taken place. Two types of decision aids were compared in a simulator study. The first involved a status display that provided information about the icing condition (i.e., wing icing vs. tailplane icing) but left the selection of appropriate responses with the pilots. The second one involved a command display that in addition to the information about the icing condition provided recommendations for proper actions (e.g., concerning appropriate pitch attitude and settings of flaps and power). Performance data assessed included, among others, how long the pilots needed to respond to the ice accretion and whether they responded in a way that effectively prevented serious consequences indicated first by a buffet of the airframe and eventually by a stall.

Compared to a baseline condition in which pilots had to manage in-flight icing encounters without any automation support, that is, by just relying on their own kinesthetic perception of changed flight dynamics, the availability of the aids increased the number of correct decisions in response to different icing encounters considerably. This finding was reflected in a significantly lower frequency of early buffets $(7.87 \%$ compared with $20.56 \%$ without support) as well as fewer stalls ( $18.08 \%$ vs. $30.00 \%)$. However, this performance benefit was observed only 
when the aid provided correct recommendations. In case of inaccurate information, the availability of the aid resulted in clear performance decrements compared with the baseline condition, with the frequency of early buffets increasing up to $73.61 \%$ and those of stalls even to $88.89 \%$.

This impairment of performance was mainly related to the pilots' inadvertently following the aids' recommendation even though the available kinesthetic cues contradicted it, hence indicating a clear tendency toward automation bias. Moreover, a significant interaction effect was found between the type and accuracy of the decision aid. Whereas both aids led to worse performance when the information provided was inaccurate compared with an accurate condition, this effect was somewhat stronger for command than for status displays. However, the effect could not be replicated in a follow-up study to this research (McGuirl \& Sarter, 2006), thus raising some doubts as to its generality.

Health care. Evidence of automation bias has also been reported in the health care domain (Alberdi, Povyakalo, Strigini, \& Ayton, 2004; Alberdi, Povyakalo, Strigini, Ayton, \& GivenWilson, 2008; McKibbon \& Fridsma, 2006; Tsai, Fridsma, \& Gatti, 2003; Westbrook, Coiera, \& Gosling, 2005). McKibbon and Fridsma (2006) and Westbrook et al. (2005) explored the effects of electronic information systems on decisions made by primary care physicians. In controlled field trials, they compared the correctness of answers to a set of standardized clinical questions provided by physicians before and after searching different electronic sources, such as PubMed, Medline, and Google. They found a small to medium ( $2 \%$ and $21 \%$, respectively) increase in the rate of correct answers attributable to the use of these sources compared with the answers provided before its consultation. Yet, in 11\% (McKibbon \& Fridsma, 2006) and 7\% (Westbrook et al., 2005) of all cases, the search of electronic sources misled the physicians, who changed an initially correct answer to an incorrect one after consulting the electronic information source.

Although these results provide evidence that physicians make commission errors when using electronic aids, the studies did not use a control group given nonelectronic resources, making any clear-cut interpretation in terms of automation bias difficult.

However, Alberdi et al. $(2004,2008)$ conducted more carefully designed studies on the effects of automated aids on clinical decision making. Experienced radiologists examined a set of mammograms either with or without the support of a detection aid that suggested areas containing lesions. Half of the mammograms contained signs of cancer, whereas the other half was free of pathology. Four different kinds of cases were compared: (a) cases in which the detection aid provided valid advice, either by correctly placing a prompt on a critical feature or by leaving a mammogram without pathological findings unmarked; (b) cases in which the aid failed to prompt critical features, that is, left a mammogram unmarked although there were signs of cancer; (c) cases in which the aid incorrectly placed a prompt in an area away from an actual sign of cancer; and (d) cases in which the aid incorrectly placed a prompt on a mammogram where in fact no signs of cancer were present. Cases of Types b and c represented false negatives that provoke omission errors if the film reader's decision making was biased by the aid's suggestion. Cases of Type d provided the opportunity for a commission error.

The results provided clear evidence for automation bias in terms of omission errors. The detection rate for "unmarked" cancers (Case b) dropped from $46 \%$ in conditions without the aid to $21 \%$ in the aided conditions, and incorrectly marked cases (c) reduced the detection rate of cancer from $66 \%$ to $53 \%$. Clearly, the film readers tended to take the absence of a computer prompt as strong evidence for the absence of cancer. The authors interpreted this finding as evidence for complacency, which they further attributed to a lack of vigilance, following the interpretation offered by Mosier and Skitka (1996) for omission errors.

In contrast to the strong evidence for omission errors, Alberdi et al. (2004) did not find evidence for commission errors in case of falsely placed prompts (Case d). However, this kind of bias was further investigated in a follow-up study (Alberdi et al., 2008). On the basis of a reanalysis of data available from a large-scale clinical trial in the United Kingdom focusing on the effectiveness of 
automated detection aids in breast screening (Taylor, Champness, Given-Wilson, Potts, \& Johnston, 2004), the authors explored the possible consequences of falsely placed prompts. The results provided some evidence, albeit weak, for automation bias in terms of commission errors. Falsely placed prompts significantly raised the probability by $12.3 \%$ that the prompted areas actually were marked as malignancy compared with an unaided condition.

Process control. Even stronger effects of automation bias have been reported in a recent series of studies investigating performance consequences of an automated decision aid in a simulated process control task (Bahner, Elepfandt, \& Manzey, 2008; Bahner, Huper, et al., 2008; Manzey, Reichenbach, \& Onnasch, 2008, 2009). In this research, the automated aid supported fault identification and management tasks by providing operators with automatically generated diagnoses for system faults and recommendations for how to deal with them. Evidence for both omission and commission errors was found, with $20 \%$ to $50 \%$ of participants committing a commission error in case the aid provided a wrong fault diagnosis for the first time (first-failure effect). Because these studies also addressed possible links between complacency and automation bias, we describe them in more detail in a subsequent section in which the two issues are discussed jointly.

Command and control. Finally, automation bias has also been recognized to represent an important issue with respect to intelligent decision support systems for command-and-control operations in the military domain (e.g., Crocoll \& Coury, 1990; Cummings, 2003, 2004; Rovira et al., 2007). According to Cummings (2004), automation bias effects in interaction with automated decision aids have contributed to several fatal military decisions, including inadvertent killing of friendly aircrews by U.S. missiles during the Iraq War. Research in this domain has addressed issues of the appropriate LOA that decision support systems should be set at and its impact on decision making in case of inaccurate recommendations (Crocoll \& Coury, 1990; Cummings, 2003; Rovira et al., 2007).

Although these studies did not provide detailed information about the frequency of omission or commission errors, their results provide additional indirect evidence for the existence of automation bias effects. For example, Rovira et al. (2007) investigated the effects of different automated aids on military decisions under time pressure. Specifically, they explored to what extent automated aids differing in LOA (information automation vs. three levels of decision automation) and overall reliability ( $60 \%$ vs. $80 \%)$ affect the speed and quality of command-and-control decisions involving the identification of most dangerous enemy targets and deciding which friendly unit might be the best choice to combat it.

As expected, all of the automated aids improved performance when they provided accurate advice. However, in case of inaccurate recommendations, clear performance costs were identified compared with an unsupported (manual) control condition. Decision accuracy declined from $89 \%$ in the manual condition to $70 \%$ in supported conditions when the aid provided incorrect recommendations, pointing to a substantial number of commission errors in the latter condition. Furthermore, some evidence was found that these effects were moderated by the LOA and the overall reliability of the aid. Performance impairments in case of inaccurate automation were most pronounced if the aid provided a high level of support of decisionmaking functions (i.e., provided a specific recommendation for an optimum decision) and when the overall level of reliability was high. Whereas the former effect parallels the findings concerning the impact of status versus command displays on automation bias in aviation (Crocoll \& Coury, 1990; Sarter \& Schroeder, 2001; see earlier discussion), the latter corresponds to the impact of reliability on complacency effects in supervisory control (Bailey \& Scerbo, 2007; R. Parasuraman et al., 1993).

\section{Factors Influencing Automation Bias}

Compared to research on automation-related complacency, considerably less is known about relevant factors that modulate the degree of automation bias. Factors to be taken into account include different aspects of system properties as well as the task context.

System properties. As should be evident from the foregoing review of research, the strength of 
automation bias effects seems to depend at least to some extent on the LOA and the reliability of an automated aid. Specifically, there is evidence that automated aids that only support processes of information integration and analysis may lead to lower automation bias effects (in terms of commission errors) than aids that provide specific recommendations for certain actions based on an assessment of the available information (Crocoll \& Coury, 1990; Rovira et al., 2007; Sarter \& Schroeder, 2001).

Another factor that may have an impact on automation bias effects includes the provision of system confidence information together with an automatically generated recommendation, as suggested by another study addressing effects of an automated aid on responses to in-flight icing encounters (McGuirl \& Sarter, 2006). Using a similar paradigm as in the study of Sarter and Schroeder (2001), they investigated effects of decision aids that not only provided information about the icing condition (status display) or specific recommendations for proper actions (command display) but also confidence values for each. The confidence information was updated on a trial-by-trial basis and was presented to the participants in a separate trend display. Providing this additional information led to less performance decrements in case of inaccurate aid recommendations compared with a condition in which the additional confidence information was not available, that is, the pilots received only information concerning the overall reliability of the aid. Clearly, pilots supported by the advanced aid were better able to assess the validity of the aids' single recommendations and to make less biased decisions about whether to comply with the aid.

Task context. Most of the available knowledge about the impact of task context factors on automation bias, thus far, has been obtained in a series of studies conducted by Mosier, Skitka, and colleagues (Mosier, Skitka, Dunbar, \& McDonnell, 2001; Skitka, Mosier, \& Burdick, 2000; Skitka, Mosier, Burdick, \& Rosenblatt, 2000). Specifically, three different factors were investigated, including social accountability, teams versus individuals, and instruction and training interventions.

Skitka, Mosier, and Burdick (2000) examined the impact of accountability on the basis of an earlier observation that suggested that the strength of automation bias in terms of omission errors might be influenced by the degree to which pilots perceive themselves as accountable for the automated tasks (Mosier et al., 1998). The experiment involved 181 nonpilots who had to complete five trials with the same W/PANES simulation described earlier. In the nonaccountable condition, participants were told that their performance would not be recorded and that the main objective of the experiment was to obtain their subjective evaluation of the task environment. Four other groups were instructed to be particularly accountable so as to reach different performance objectives (e.g., maximize overall performance, tracking performance, or speed or accuracy in the waypoint and gauge-monitoring tasks) and that they would have to justify their performance in a debriefing interview after the experiment.

The authors found that participants who were instructed to be accountable for overall performance or the accuracy in the waypoint and gauge-monitoring tasks committed significantly less omission and commission errors than did the participants of the nonaccountable group or the groups who particularly were made accountable for quick responses or their specific performance in the tracking task. Furthermore, participants who felt responsible for overall performance or accuracy also showed more attentive automation verification behavior than did participants in all the other groups. The latter effect was shown by providing participants a second monitor with which they could actively check the validity of any recommendations provided by the aid in case of doubts. Participants in the nonaccountable group made significantly less use of this device than participants feeling accountable for overall performance or the accuracy of the automated tasks. An even smaller tendency to cross-check the automation was found in groups who felt particularly accountable for response speed or tracking performance, respectively. Although these results may be taken as evidence that accountability might be a relevant factor reducing automation bias, the results are not fully conclusive in this respect. An alternative view is that the results might reflect a higher level of motivation and effort in the accountable groups induced by providing participants 
of these groups with some specific performance goals (Locke \& Latham, 1990).

Another set of two experiments explored to what extent the presence of a second crewmember in combination with several training interventions or explicit prompts to cross-check the automation would moderate the degree of automation bias (Mosier et al., 2001; Skitka, Mosier, Burdick, et al., 2000). The first of these studies (Skitka, Mosier, Burdick, et al., 2000) again involved nonpilots working on the W/PANES task. In the two-person conditions, both crewmembers had individual tasks but were instructed to work redundantly on the waypoint or gaugemonitoring task. Training interventions included various briefings, ranging from just alerting participants to verify the automation to a detailed briefing about the nature of omission and commission error as risk factors in human-automation interaction. In addition, conditions were compared in which the participants did or did not receive explicit prompts to verify the automation, which in the first case were presented along with the aid's directive.

The presence of a second crewmember did not affect the strength of automation bias for either omission or commission errors. This overall pattern of effects was replicated in a second study involving 48 experienced glass cockpit pilots (Mosier et al., 2001). The pilots were required to perform missions in a part-task flight simulator similar to those in the previously described study of Mosier et al. (1998). Neither detrimental nor beneficial effects of crew versus individual performance were found with respect to omission and commission errors. Furthermore, neither of the training and instruction interventions had any effect on the strength of automation bias. However, what was found is that the rate of omission errors varied between individual participants and with the criticality of events in terms of possible consequences if they were missed. The latter effect confirms earlier results of Mosier et al. (1998) and may be taken as evidence that automation bias might not be related just to an automation-induced vigilance decrement but to a reallocation of attentional resources attributable to a delegation of responsibility to the automated aid. However, this reallocation of resources does not seem to be used to improve performance in concurrent tasks, a finding that provides some support for the cognitive-miser hypothesis of automation bias.

\section{Summary}

Human decision making can be biased when supported by imperfect automated decision aids. Whereas this bias is relatively benign and actually can be beneficial when a decision aid provides correct recommendations (e.g., by speeding up decision making), it results in omission and commission errors when the decision aid is wrong. Evidence of both kinds of errors has been reported from several domains, including aviation, medicine, process control, and commandand-control operations in military contexts.

The results show that automation bias represents a robust phenomenon that (a) can be found in different settings, (b) occurs in both naive and expert (e.g., pilots) participants, (c) seems to depend on the LOA and the overall reliability of an aid, (d) cannot be prevented by training or explicit instructions to verify the recommendations of an aid, (e) seems to be depend on how accountable users of an aid perceive themselves for overall performance, and (f) can affect decision making in individuals as well as in teams. Interestingly, the first four of these results have also been found in studies of automation-related complacency (the fifth, that is, impact of accountability on complacency, and sixth, that is, complacency in teams, have notyet been systematically investigated). The common findings suggest that complacency and bias might be linked, a possibility that we discuss in more detail in the next section.

\section{TOWARD AN INTEGRATED MODEL OF COMPLACENCY AND BIAS}

\section{Theoretical Links}

Although the concepts of complacency and automation bias have been discussed separately as if they were independent, they share several commonalities, suggesting they reflect different aspects of the same kind of automation misuse (cf. R. Parasuraman \& Riley, 1997). Omission errors with decision-aiding systems provide the most obvious link between the two concepts, given that they occur when decision makers fail to act because they were not informed of an imminent system problem by the automation. 
Human operators thus rely on the alerting function of the aid at the expense of attentive monitoring of important environmental cues. Such inadequate monitoring clearly corresponds to automation-induced complacency (Mosier \& Skitka, 1996).

Similarly, complacency-like effects may also be responsible for the occurrence of commission errors. According to Skitka et al. (1999), "Commission errors can be the result of not seeking out confirmatory or disconfirmatory information, or discounting other sources of information in the presence of computer-generated cues" (p. 993). The latter alternative, discounting of contradictory information, reflects bias in decision making in a strict sense. Having contradictory information from different sources, the operator, for some reason, cedes greater authority to the automated aid than to the other sources. This attitude could reflect greater trust in automation than in one's own ability or difficulties to comprehend the perceived information correctly.

However, the former alternative, following the aid's recommendation without verification, reflects a qualitatively different kind of decision bias. In this case, the bias in favor of an automated aid is expressed in operators' relying so much on the proper function of an aid that they neglect their own sampling of information and become more selective in attending to different information sources. This kind of automation bias resembles what has been referred to as automation complacency in supervisory control tasks, given that the failure to verify (not attending to the raw data) indicates a reallocation of attention.

Furthermore, the cognitive-miser hypothesis of automation bias in high task load situations could also reflect complacency in addition to a strict decision bias. Similar to the operator who tends to monitor an automated process inadequately if the workload is high, the user of a decision aid may trust it to the extent that he or she directly follows the automatically generated advice without making the attentionally demanding effort of cross-checking its validity against other available and accessible information. This view points to an overlap between the concepts of automation complacency and bias and suggests that at least some instances of commission errors might be explained within the same attentional framework suggested for complacency and shown previously in Figure 3, substituting "Information Source A" for "Task A," and so on.

To date, there is little empirical evidence to allow for an assessment to what extent commission errors truly represent a bias in weighting information from different sources (automation vs. own information sampling) or a decision bias reflected in neglecting to verify automation. However, the previously described findings of Skitka et al. (1999; Skitka, Mosier, \& Burdick, 2000) do support the view that neglect of automation verification might constitute a major source of commission errors, as does a study by Bahner, Huper, et al. (2008), which we describe later.

\section{Common Issues}

The concepts of complacency and automation bias can be viewed as indications of automation misuse, that is, as a behavioral consequence related to inappropriate overreliance on automation. This characterization was challenged by Moray (2003; Moray \& Inagaki, 2000), at least with respect to complacency. Moray proposed that what has been characterized as "complacent" behavior, that is, operators' neglecting to monitor automation, in fact may represent a rational strategy. Moray argued that when operators have several tasks to attend to, their monitoring of automation should be in proportion to its perceived reliability. Given that highly reliable automation will fail only very rarely, then the rational strategy would be to monitor it also only very infrequently. A natural consequence of such a monitoring strategy is that when operators have other tasks to perform they will occasionally miss automation failures because their attention will be allocated elsewhere.

Up to this point, Moray's (2003; Moray \& Inagaki, 2000) argument does not differ from the framework for complacency we have presented that links it to a multitask attentional strategy (Figure 3). However, Moray went further in arguing that complacency should be inferred only if operators monitor automation less frequently than the optimal value for a particular system. If, on the other hand, they monitor 
more often than the optimal value, they could be called "skeptical." Moray suggested that an operator who monitored at the optimal frequency should be characterized as "eutactic" or "well calibrated" - similar to the concept of an operator whose trust is calibrated to the actual reliability of automation (Lee \& See, 2004). What is the optimal (or normative) monitoring rate? Moray suggested that the ShannonWeaver-Nyquist sampling theorem provides a basis for determining the optimum. This theorem states that to perfectly reproduce a continuously varying process (e.g., an analog signal) from intermittent samples (e.g., digital values), the frequency of sampling should be at least twice the frequency of the highest frequency in the continuous or analog signal.

Does human sampling behavior also follow the sampling theorem? An early study by Senders (1964) provides some supporting evidence. He had participants monitor up to six gauges with continuously varying values to detect out-oflimit targets. The frequency (or bandwidth) of the continuously varying signals ranged from slow to fast. Senders found that participants' fixations on a particular gauge were directly proportional to the bandwidth of the signal displayed on that gauge (see also Moray, 1984).

Moray and Inagaki's (2000) suggestion concerning the necessity of comparing actual and optimal monitoring rates in automated systems is important. However, their proposal that the sampling theorem provides a basis for determining the optimal rate for monitoring is difficult to test outside of simple laboratory experiments (as in Senders, 1964), because the frequency content of many real-world information sources is difficult or impossible to compute. Nevertheless, there may be other ways in which a normative value for monitoring automation can be calculated, as described in a later section. Moreover, the sampling models posited by Moray (2003; Moray \& Inagaki, 2000) and Senders (1964) do not consider the potential cost of sampling (e.g., extensive eye or head movements or search time) or the value provided by sampled information, which can pose severe limits on the rate of sampling (Sheridan, 1970, 2002). The salience, effort, expectancy, and value (SEEV) model of Wickens et al. (2007), on the other hand, does include such cost and value parameters and has been found to explain well observers' visual scanning patterns (or lack thereof) in a number of different tasks.

We agree with Moray and Inagaki's (2000) view that complacency should ideally be evaluated independently of the outcome of insufficient monitoring-for example, not detecting an automation failure. Most previous studies, including the first study by Parasuraman et al. (1993), inferred complacency from detection performance alone and not from an independent measure of monitoring. Studies measuring eye movements provide an exception (Bagheri \& Jamieson, 2004; Metzger \& Parasuraman, 2005), but eye fixation rates still need to be compared with optimal monitoring rates. Hence, Moray and Inagaki suggested that studies on complacency to date had not provided convincing evidence for the phenomenon of automation-related complacency.

Moray and Inagaki's (2000) critique can also be applied to studies on automation bias. As described previously, although operators commit omission or commission errors in using such aids, such errors may not necessarily indicate that the operators were complacent. Such a conclusion would be warranted only if it could be shown that these performance consequences indeed were related to operators' monitoring or verifying automation behavior less frequently than the rate indicated by a normative model.

\section{Evidence for an Integrative Concept of Complacency and Automation Bias}

A recent series of experiments has taken this caveat into account and provided evidence for the proposed link between complacency and automation bias (Bahner, Elepfandt, et al., 2008; Bahner, Huper, et al., 2008; Manzey et al., 2009; Manzey, Reichenbach, et al., 2008). These studies involved the use of a process control microworld (AutoCAMS; Lorenz, Di Nocera, Rottger, \& Parasuraman, 2002; Manzey, Bleil, et al., 2008) that simulates an autonomous life support system for a space station consisting of five subsystems (e.g., $\mathrm{O}_{2}, \mathrm{CO}_{2}$, pressure) critical to maintaining cabin atmosphere. The primary task of the operator involved supervisory control of the different subsystems, including diagnosis 
and management of system faults, which occurred occasionally and unpredictably. Operators also had two secondary tasks: a prospective memory task and a simple reaction time task. The primary task was supported by an automated aid that, in case of failures of single subsystems, provided an automatically generated fault diagnosis as well as recommendations for fault management.

Bahner, Huper, et al. (2008) had two groups of well-trained engineering students perform the AutoCAMs simulation. One group was told that the aid would work highly reliably, although not perfectly, and that they should carefully cross-check each diagnosis before accepting it (information group). The second group received the same information but was additionally exposed to some rare automation failures during training (experience group). Automation failures could include a failure of the diagnostic function, that is, the aid provided wrong diagnoses for 2 out of 10 system faults (Bahner, Huper, et al., 2008), or a failure of the alarm function, that is, the aid failed to indicate 2 out of 10 system faults (Bahner, Elepfandt, et al., 2008). On the basis of earlier research (e.g., Lee \& Moray, 1992), it was assumed that the practical experience of automation failures should reduce overall trust in the system.

Bahner, Huper, et al. (2008) assessed complacency by measuring the extent to which participants verified the automation's diagnosis before accepting it. Participants were provided independent access (via mouse click) to all relevant system information (e.g., tank levels, flow rates at different valves, history graphs displaying the time course of system parameters), needed to verify the aid's diagnoses. This procedure allowed the investigators to assess the level of operator complacency in interaction with the aid by contrasting the actual information sampling behavior of operators with a "normative model" of optimal behavior. According to this logic, any participant who accessed just the information appropriate to verify a given diagnosis before accepting it was regarded as showing noncomplacent (eutactic) behavior in interaction with the aid. However, participants sampling less information than that necessary to completely verify the aid's recommendation were regarded as complacent to different degrees, dependent on how much they deviated from the optimal sampling strategy. This operational definition of complacency made it possible to evaluate the level of complacency in interaction with the aid independent of its possible performance consequences.

These results provide direct empirical evidence for the proposed relationship between perceived reliability of automation, complacency, and automation bias. In both experiments, participants of all experimental groups exhibited a complacency effect at least to some extent, that is, did not fully verify the automatically generated diagnoses for system faults completely before accepting it. Figure 4 from Bahner, Huper, et al. (2008) shows that operators in the information group were more complacent (sampled fewer parameters) than were those in the experience group. This figure also shows that the degree of operator verification was less than that required by the normative model, irrespective of training. Yet, as expected, the degree of the complacency effect was moderated by the experiences the participants had with the aid during training. Participants who were exposed to failures of the diagnostic function of the aid, but not those exposed to failures of the alarm function (Bahner, Elepfandt, et al., 2008), showed a significantly lower level of complacency than participants who were informed just that the aid may fail.

In addition, a clear link between the level of complacency and automation bias was also found: $21 \%$ of participants committed commission errors, which occurred despite the fact that the automation error could easily be recognized (Bahner, Huper, et al., 2008). Analyses of informationsampling behavior revealed that these errors indeed were related to a generally higher level of complacency in this subgroup of participants compared with those who did not commit this kind of error (see Figure 5). Bahner, Elepfandt, et al. (2008) found even more participants (18 out of 24) committed a commission error when the aid provided a wrong diagnosis for the first time. Inspection of the verification behavior just before committing the error again revealed that $80 \%$ of the participants followed the false recommendation because of insufficient 


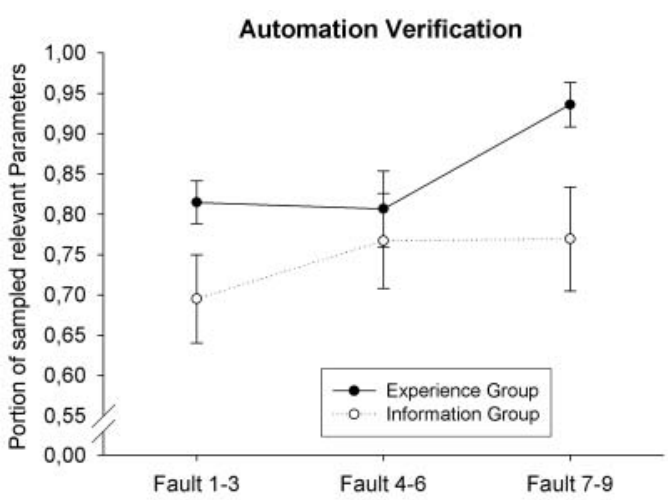

Figure 4. Proportion of parameters sampled prior to acting on the recommendation of an automated decision aid, for different faults and for the information and experience groups. From "Misuse of Automated Decision Aids: Complacency, Automation Bias and the Impact of Training Experience,” by E. Bahner, A.-D. Huper, and D. Manzey, 2008, International Journal of HumanComputer Studies, 66, p. 694. Copyright 2008 by Elsevier Science. Reprinted with permission.

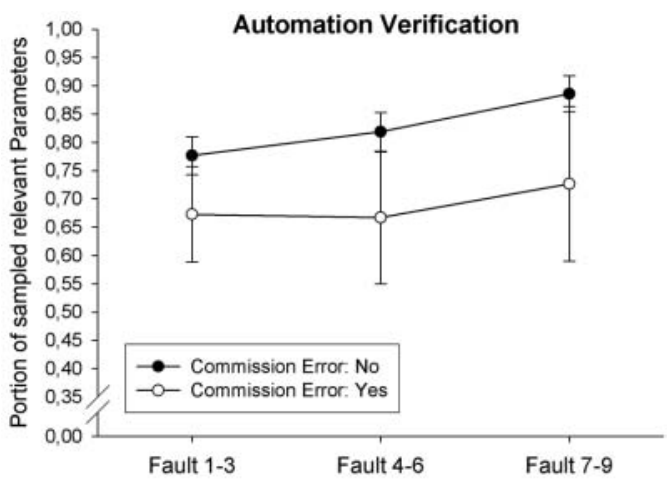

Figure 5. Proportion of relevant parameters sampled among participants who did and did not commit a commission error. From "Misuse of Automated Decision Aids: Complacency, Automation Bias and the Impact of Training Experience," by E. Bahner, A.-D. Huper, and D. Manzey, 2008, International Journal of Human-Computer Studies, 66, p. 695. Copyright 2008 by Elsevier Science. Adapted with permission.

cross-checking of the relevant system information needed to verify the aid's recommendation. Yet $20 \%$ of the participants followed the recommendation despite seeking out all parameters necessary to verify that the automated advice was wrong.

The underlying determinants of this latter effect were further investigated in a follow-up experiment (Manzey, Reichenbach, et al., 2008) in which participants worked with three different decision aids that differed in their amount of support (LOA). The first aid provided only an automatically generated diagnosis for a given system fault but left it to the operator to plan and implement all necessary actions; the second one provided additional recommendations for necessary actions, which, however, had then to be implemented manually by the operator; and the third performed fault management autonomously if the operator confirmed the proposed diagnosis and plan of interventions.

Independent of the LOA of the decision aid, approximately $43 \%$ of operators did not detect a wrong diagnosis of the aid when it occurred for the first time. Analyses of information-sampling behavior revealed that half of the participants made this commission error because of a clear complacency effect, as reflected in an incomplete sampling of information needed for automation verification. The other half of participants again committed this kind of error despite the fact that they had sampled all system parameters necessary to verify the diagnosis provided by the aid.

However, more detailed analyses of this effect revealed an interesting difference between these participants and participants who detected the wrong diagnosis. Participants who correctly recognized that the aid's advice was wrong showed a sharp increase in the average time needed to process a sampled system parameter in case that its information did not fit the diagnosis of the aid, compared with trials in which the aid's diagnoses were correct. Clearly, these participants became aware of the contradictory information and needed time to evaluate it. However, this effect did not emerge for participants who sampled all relevant information but nevertheless committed a commission error. These participants did not show any difference in processing time when the aid's diagnosis was correct and when it was wrong.

Given this finding, the commission error committed by these participants cannot be explained by a decision bias view associated with a 
discounting of contradictory information. In addition, an explanation in terms of confirmation bias in processing the sampled information or difficulties of comprehension is also unlikely, given that the participants were very well trained and that the system parameter always contradicted the aid's diagnosis in an unequivocal way. Thus, the two types of decision bias discussed previously, confirmation bias and discounting bias, can be ruled out as explanations, at least for this group. Rather, the commission errors in this group seem to be attributable to a sort of looking-but-not-seeing effect, analogous to what in other contexts has been referred to as "inattentional blindness" (Mack \& Rock, 1998) and which also has been suggested to underlie complacency effects in supervisory control tasks (Duley et al., 1997).

Direct evidence for this latter interpretation was provided by another AutoCAMS experiment that investigated this hypothesis in more detail (Reichenbach, Onnasch, \& Manzey, in press). In this study, the simulation was stopped immediately after the participants had committed a commission error, and the participants were required to report (a) what system parameters they had accessed to verify the aid's recommendation and (b) what the values of these parameters were. Out of the 11 participants committing a commission error in this study, 6 were found to have sampled only part of the system information that would have been necessary to check to verify the aid's advice. The remaining 5 participants committed the commission error despite checking all the parameters that were necessary to realize that the automatically generated diagnosis was wrong. However, only 1 of them actually was aware of all the contradictory information but failed to give an explanation for the final decision to nevertheless follow the aid.

The other 4 participants were not able to recall correctly the information they had accessed. Instead, they tended to report system values that would have to be expected, given that the advice of the aid would have been correct. This effect replicates the phantom memory effect reported by Mosier et al. (1998). However, given that the actual system values always differed considerably from the ones to be expected, this effect seems to be more related to a hindsight justification of the final decision than to a misreading of the parameters.

This finding is particularly interesting because it provides evidence that commission errors associated with complete (optimal) information sampling may result not necessarily from a misweighting of contradictory information but from a complacency-like, covert attention effect (Duley et al., 1997), which, in this case, was reflected in a withdrawal of attentional resources from processing the available (and looked-at) information.

In summary, two main conclusions can be drawn from these results. The first is that it is necessary to decompose the underlying determinants of commission errors that operators make while interacting with automated decision aids. Three different sources can be distinguished: (a) an actual, overt redirection of visual attention in terms of reduced proactive sampling of relevant information needed to verify an automated aid; (b) a more subtle effect reflected in less attentive processing of this information, perhaps because covert attention is allocated elsewhere (an effect analogous to inattentional blindness); and (c) an active discounting of information that contradicts the recommendation of the aid because of either difficulties in comprehension or an overreliance on the automated source.

The first two of these sources relate the occurrence of automation bias to issues of selective or less attentive processing of information and seem to constitute a major source of bias in human interaction with decision aids. Such an effect provides strong evidence that not only omission errors but also commission errors can be related to essentially the same attentional processes that have been shown to underlie complacency effects in supervisory control tasks. This parallelism further suggests that what has been referred to as complacency in supervisory control studies (R. Parasuraman et al., 1993) and automation bias in studies examining use of decision aids (Mosier \& Skitka, 1996), at least to a large extent, might represent different manifestations of overlapping automation-induced phenomena.

Second, given the operational definition of complacency and automation bias in the set of 
studies we have described (e.g., Bahner, Huper, et al., 2008; Manzey et al., 2009), the view that the observed effects reflect an inevitable side effect of a rational strategy used by operators in interacting with automated systems can be ruled out, as confirmed by a contrast of the actual automation verification behavior of operators with a normative (rational) model of information sampling, as suggested by Moray and Inagaki (2000). The results instead support the view that complacency and automation bias indeed represent a human performance cost of certain automation system designs, that is, systems characterized by high reliability and high levels of automation, particularly in high task load situations. Such costs need to be considered as potentially serious risk factors when evaluating the overall efficiency and safety of human-automation systems.

\section{An Integrated Model of Complacency and Automation Bias}

Our analysis suggests that automation-induced complacency and automation bias represent closely linked theoretical concepts that show considerable overlap with respect to the underlying processes. We propose an integration such that they represent different manifestations of similar automation-induced phenomena, with attention playing a central role. Furthermore, complacency and automation bias, although affected by individual differences, cannot be considered as just another type of human error but constitute phenomena that result from a complex interaction of personal, situational, and automation-related characteristics.

An integrated model of complacency and automation bias is shown in Figure 6. Note that this model is not meant to cover all kinds of automation bias but only those that are related to a selective or less attentive processing of information. Furthermore, the model does not address instances of complacency and automation bias that solely reflect performance consequences stemming from operators' lacking appropriate system knowledge, that is, instances in which the automated system has to be relied on because the human operator does not possess the necessary competency or knowledge to verify its proper function.

The three main critical features of this model include (a) the distinction between two aspects of complacency and automation bias, referred to as "complacency potential" and "attentional bias" in information processing; (b) the differentiation between automation-induced attentional phenomena and its possible performance consequences in terms of omission and commission errors; and (c) the dynamic and adaptive nature of complacency and automation bias, reflected in the two feedback loops.

The first distinction capitalizes on a similar conceptual differentiation between two different aspects of complacency first proposed by Singh et al. (1993a, 1993b) and later adopted by Manzey and Bahner (2005). Complacency potential is conceived of as a behavioral tendency to react in a less attentive manner in interacting with a specific automated system. It is assumed to be influenced by the (perceived) reliability and consistency of the system, the history of experiences of the operator with this system (see later discussion), and individual characteristics of the human operator. The assumption that this tendency to overrely on a certain system is system specific contrasts with earlier conceptions that have conceived of complacency potential as a general tendency toward automation in general (Singh et al., 1993a). However, previous findings (Prinzel, 2002; Prinzel et al., 2001) indicate that both perceived system characteristics as well as individual differences determine the final level of complacency in supervisory control of an automated system.

Relatively less is known about the nature of individual characteristics contributing to differences in complacency potential. As has been discussed in some detail previously, differences in attitudes toward technology may play a role. Yet other findings suggest that personality traits might also contribute to individual differences in complacency, for example, self-efficacy (Prinzel, 2002), as well as trust in automation in general (Merritt \& Ilgen, 2008). Clearly, more research is needed in this area.

However, even high complacency potential does not guarantee that individuals will necessarily exhibit selective or less attentive information processing in interaction with an automated system. As shown earlier, complacency and automation bias effects emerge primarily when 


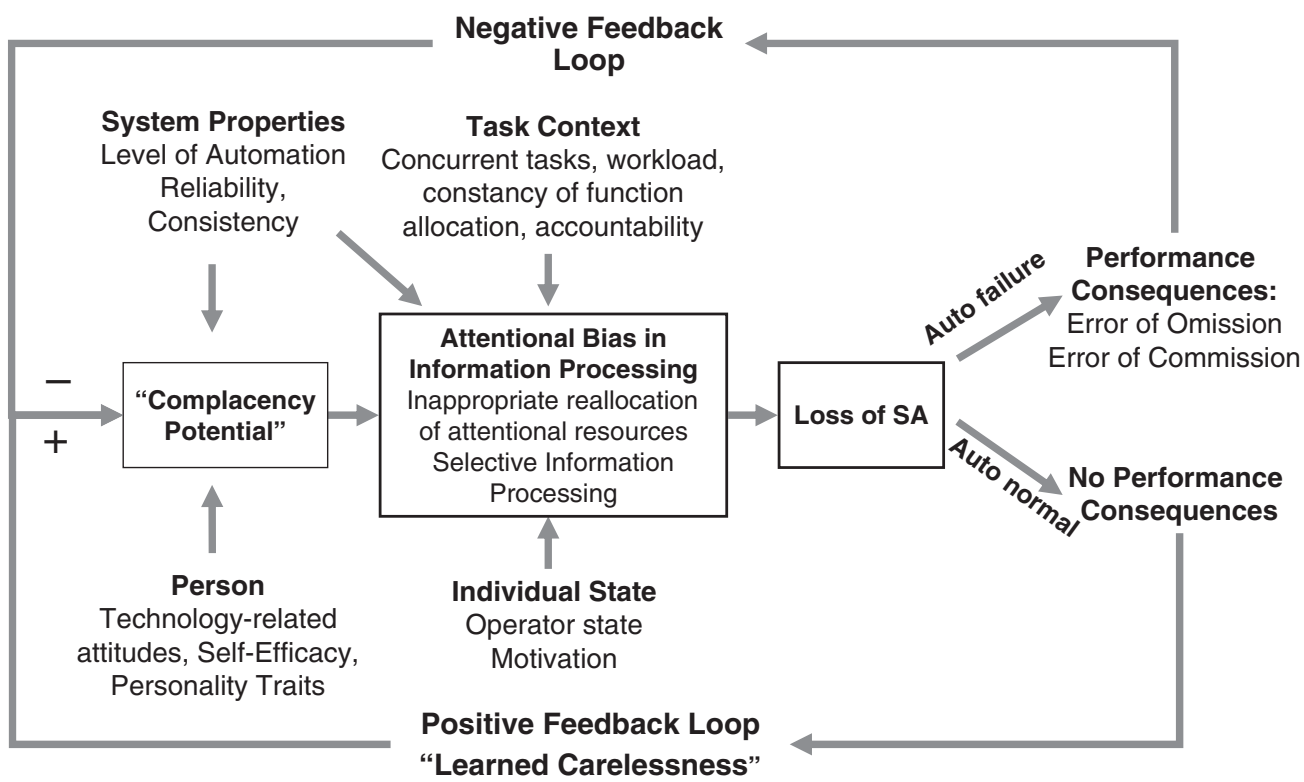

Figure 6. An integrated model of complacency and automation bias.

task load is high (e.g., multitask demands). This fits with the general understanding of complacency and automation bias as representing issues related to task prioritization and allocation of attentional resources. Furthermore, operator state variables may also influence to what extent high complacency potential leads to an overt attentional bias in interaction with automation. For example, a recent study found that fatigued operators interacted in a more careful and less complacent manner with a decision aid than did alert operators (Manzey et al., 2009).

A second important feature of the integrated model represents the distinction between complacency and automation bias as an attentional effect and its performance consequences in terms of omission or commission errors. This distinction directly relates to the analysis of the link between complacency and automation bias presented previously. It emphasizes that complacency and automation bias in interaction with automated systems is reflected in an automationinduced withdrawal or reallocation of attentional resources. These attentional effects constitute a conscious or unconscious response of the human operator induced by overtrust in the proper function of an automated system. In this sense, the effects reflect what Mosier and Skitka (1996) described as a "heuristic use of automation" that may or may not lead to overt performance consequences, depending on whether the automation fails. More specifically, the model assumes that the immediate performance consequence of a selective or less attentive processing of information is a loss of situation awareness. This has no consequences as long as the automation works properly but directly leads to errors of omission or commission in case of automation failure.

This aspect of the model has particular implications for an appropriate operational definition of the concepts of complacency and automation bias in future research. Specifically it suggests that operational definitions of complacency or automation bias as behavior need to be based on direct or indirect behavioral indicators of attention allocation. Direct indicators may be derived from eye-tracking analyses or other indicators of monitoring or information-sampling behavior. Indirect indicators of attention may include assessments of a reallocation of attentional resources by means of secondary-task methods. However, as proposed by Moray (2003; Moray \& Inagaki, 2000), the mere fact that automated systems influence allocation of attentional resources cannot be regarded as an indication of complacency or automation bias. Such a 
conclusion is justified only if the observed effects are compared with some normative model of "optimal attention allocation" in interaction with a given system. Defining appropriate normative models for interaction with given automated systems represents an important challenge for future research.

Finally, following an earlier proposal by Manzey and Bahner (2005), the model conceives of complacency and automation bias as resulting from an adaptive process that dynamically develops over time on the basis of experiences an operator has in interaction with an automated system. As shown in Figure 6, there is a positive feedback loop that leads to a rise in complacency potential over time. Given the usually high reliability of automated systems, even highly complacent and biased behavior of operators rarely leads to obvious performance consequences. Over time, the lack of performance consequences might affect complacency potential by inducing a cognitive process that resembles what has been referred to as "learned carelessness" in the domain of work safety (Frey \& Schulz-Hardt, 1997) and has already been included in cognitive models of pilot performance (Luedtke \& Moebus, 2005).

On the other hand, experiences of automation failures can be assumed to initiate a negative feedback loop, reducing the complacency potential in interaction with a given system. This pattern is suggested by empirical results showing that even single automation failures may considerably reduce the trust in an automated system (Lee \& Moray, 1992; Madhavan, Wiegmann, \& Lacson, 2006) and also affect the strength of complacency and automation bias effects (Bahner, Huper, et al., 2008). In this respect, our model of complacency and automation bias resembles the more general model of trust and reliance in automation proposed by Lee and See (2004) that includes similar feedback loops.

\section{CONCLUSION}

Automation-related complacency and automation bias have previously been viewed as two separate and independent potential human performance costs of certain automation designs. Automation complacency is generally found in multitasking environments where operators have to perform manual tasks as well as supervise automation. Automation complacency can thus be understood in terms of an attention allocation strategy whereby the operator's manual tasks are attended to at the expense of the automated task. Automation bias is reflected in omission and commission errors made by operators interacting with imperfect decision aids. Automation bias can be conceived of as a special case of human decision biases, such as confirmation bias and discounting bias. However, recent evidence suggests that at least some forms of automation bias result from attentional processes similar to those involved in automation-related complacency. Thus, complacency and automation bias represent different manifestations of overlapping automation-induced phenomenon, with attention at the center.

Our integrated attentional model provides a heuristic framework for further research on complacency and automation bias. The model proposes that attentional factors contribute to some but not all forms of automation bias. This suggests that future research would be desirable on the relative importance of attentional effects versus discounting of contradictory information as determinants of automation bias. This goal could be achieved through additional studies that not only investigate the performance consequences of automation bias but also conduct microanalyses of informationsampling strategies, using either eye-tracking or explicit verification procedures as developed by Bahner, Huper et al. (2008) or both. In particular, the extent to which contradictory information is available, its saliency, and the cost of obtaining it may determine the degree of influence of attentional factors.

In addition, further research is required on the relative importance and interplay of the two proposed feedback loops in our integrated model (see Figure 6). We propose a positive feedback loop that increases complacency potential while negative feedback reduces it. Studies that varied the relative effectiveness of these feedback loops would allow for a better understanding of the dynamics of development of complacency and automation bias in human interaction with automation. 
Finally, individual differences were considered only briefly in this article, but there is preliminary evidence that personal, experiential, and situational factors influence automation complacency and bias. There is currently growing interest in using knowledge of individual differences to improve design and training efforts in human factors and ergonomics generally (Szalma, 2009). Similar research in the area of automation complacency and bias would appear to be worthwhile.

Our integrated model of automation complacency and bias also provides a framework within which practical applications, particularly those aimed at mitigating complacency and bias in automated systems, can be better examined. Several studies have shown that the LOA and the type of processing supported by automation can affect its benefits and costs, including complacency and situation awareness (R. Parasuraman et al., 2000). There is also preliminary evidence that automation bias can be mitigated with aiding of information analysis as opposed to decision support, although additional research is needed to confirm the efficacy of this design option.

Additional promising points of attack include a change of situational conditions (including function allocation; see Manzey, Reichenbach, et al., 2008; Parasuraman, Mouloua, \& Molloy, 1996) or providing practical experience with a given automated system. Changes of situational conditions may include taking actions to raise the perceived accountability of operators or using flexible strategies of function allocation, which both have been shown to reduce issues of complacency and automation bias in interaction with different automated systems (R. Parasuraman et al., 1996; Skitka, Mosier, \& Burdick, 2000). Our integrated model also suggests the importance of a negative feedback loop in minimizing complacency and bias effects (see Figure 6), which could be used to make users of automated systems more resilient to complacency and automation bias effects.

\section{KEY POINTS}

- Complacency and automation bias are phenomena that describe a conscious or unconscious response of the human operator induced by overtrust in the proper function of an automated system.
- Although both concepts have been described separately, they share several commonalities with respect to the underlying attentional processes.

- Empirical evidence suggests that attentional factors contribute to many but not all forms of automation bias.

- An integrated model is presented that views complacency and automation bias as resulting from a complex interplay of personal, situational, and automation-related factors.

- The integrated model can provide design guidance and serve as a heuristic framework for further research.

\section{REFERENCES}

Alberdi, E., Povyakalo, A. A., Strigini, L., \& Ayton, P. (2004). Effects of incorrect computer-aided detection (CAD) output on human decision-making in mammography. Academic Radiology, 11, 909-918.

Alberdi, E., Povyakalo, A. A., Strigini, L., Ayton, P., \& GivenWilson, R. (2008). CAD in mammography: Lesion-level versus case-level analysis of the effects of prompts on human decisions. International Journal of Computer-Assisted Radiology and Surgery, 3, 115-122.

Bagheri, N., \& Jamieson, G. A. (2004). Considering subjective trust and monitoring behavior in assessing automationinduced "complacency." In D. A. Vicenzi, M. Mouloua, \& O. A. Hancock (Eds.), Human performance, situation awareness, and automation: Current research and trends (pp. 54-59). Mahwah, NJ: Erlbaum.

Bahner, J. E., Elepfandt, M., \& Manzey, D. (2008). Misuse of diagnostic aids in process control: The effects of automation misses on complacency and automation bias. In Proceedings of the 52nd Meeting of the Human Factors and Ergonomics Society (pp. 1330-1334). Santa Monica, CA: Human Factors and Ergonomics Society.

Bahner, E., Huper, A.-D., \& Manzey, D. (2008). Misuse of automated decision aids: Complacency, automation bias and the impact of training experience. International Journal of HumanComputer Studies, 66, 688-699.

Bailey, N., \& Scerbo, M. S. (2007). Automation-induced complacency for monitoring highly reliable systems: The role of task complexity, system experience, and operator trust. Theoretical Issues in Ergonomics Science, 8, 321-348.

Bainbridge, L. (1983). Ironies of automation. Automatica, 19, 775-779.

Billings, C. E., Lauber, J. K., Funkhouser, H., Lyman, G., \& Huff, E. M. (1976). Aviation Safety Reporting System (Technical Report TM-X-3445). Moffett Field, CA: National Aeronautics and Space Administration Ames Research Center.

Casey, S. M. (1998). Set phasers on stun: And other true tales of design, technology, and human error. Santa Barbara, CA: Aegean.

Corbetta, M. (1998). Frontoparietal cortical networks for directing attention and the eye to visual locations: Identical, independent, or overlapping neural systems? Proceedings of the National Academy of Sciences (USA), 95, 831-838.

Craig, A. (1984). Human engineering: The control of vigilance. In J. S. Warm (Ed.), Sustained attention in human performance (pp. 247-291). New York, NY: Wiley. 
Crocoll, W. M., \& Coury, B. G. (1990). Status or recommendation: selecting the type of information for decision aiding. In Proceedings of the Human Factors Society 34th Annual Meeting (pp. 1525-1528). Santa Monica, CA: Human Factors and Ergonomics Society.

Cummings, M. L. (2003). Designing decision support systems for revolutionary command and control domains $(\mathrm{PhD}$ dissertation). University of Virginia, Charlottesville.

Cummings, M. L. (2004, September). Automation bias in intelligent time critical decision support systems. Paper presented to the American Institute for Aeronautics and Astronautics First Intelligent Systems Technical Conference, Reston, VA. Retrieved from http://citeseerx.ist.psu.edu/ viewdoc/summary?doi=10.1.1.91.2634

Davies, D. R., \& Parasuraman, R. (1982). The psychology of vigilance. London, England: Academic Press.

Degani, A. (2001). Taming Hal: Designing interfaces beyond 2001. New York, NY: Macmillan.

Dekker, S. W. A., \& Hollnagel, E. (2004). Human factors and folk models. Cognition, Technology, and Work, 6, 79-86.

Dekker, S. W. A., \& Woods, D. D. (2002). MABA-MABA or abracadabra? Progress on human automation coordination. Cognition, Technology, and Work, 4, 240-244.

de Visser, E., \& Parasuraman, R. (2007). Effects of imperfect automation and task load on human supervision of multiple uninhabited vehicles. In Proceedings of the 51st Annual Meeting of the Human Factors and Ergonomics Society (pp. 1081-1085). Santa Monica, CA: Human Factors and Ergonomics Society.

De Waard, D., van der Hulst, M., Hoedemaeker, M., \& Brookhuis, K. A. (1999). Driver behavior in an emergency situation in the automated highway system. Transportation Human Factors, 1, 67-82.

Domeinski, J., Wagner, R., Schoebel, M., \& Manzey, D. (2007). Human redundancy in automation monitoring: Effects of social loafing and social compensation. In Proceedings of the Human Factors and Ergonomics Society 51st Annual Meeting (pp. 587-591). Santa Monica, CA: Human Factors and Ergonomics Society.

Duley, J. A., Westerman, S., Molloy, R., \& Parasuraman, R. (1997) Effects of display superimposition on monitoring of automation. In Proceedings of the 9th International Symposium on Aviation Psychology (pp. 322-326). Columbus, OH: Association of Aviation Psychology.

Dzindolet, M. T., Beck, H. P., Pierce, L. G., \& Dawe, L. A. (2001). A framework of automation use (Report No. ARL-TR-2412). Aberdeen Proving Ground, MD: Army Research Laboratory.

Dzindolet, M. T., Pierce, L. G., Beck, H. P., \& Dawe, L. A. (2002). The perceived utility of human and automated aids in a visual detection task. Human Factors, 44, 79-94.

Frey, D., \& Schulz-Hardt, S. (1997). Eine Theorie der gelernten Sorglosigkeit [A theory of learned carelessness]. In H. Mandl (Ed.), Bericht über den 40. Kongress der Deutschen Gesellschaft für Psychologie (pp. 604-611). Goettingen, Germany: Hogrefe.

Funk, K., Lyall, B., Wilson, J., Vint, R., Niemczyk, M., Suroteguh, C., \& Owen, G. (1999). Flight deck automation issues. International Journal of Aviation Psychology, 9, 109-123.

Galster, S., Duley, J. A., Masalonis, A., \& Parasuraman, R. (2001). Air traffic controller performance and workload under mature Free Flight: Conflict detection and resolution of aircraft selfseparation. International Journal of Aviation Psychology, 11, 71-93.

Galster, S., \& Parasuraman, R. (2001). Evaluation of countermeasures for performance decrements due to automated-related complacency in IFR-rated general aviation pilots. In Proceedings of the International Symposium on Aviation Psychology (pp. 245-249). Columbus, OH: Association of Aviation Psychology.

Gigerenzer, G., \& Todd, P. A. (1999). Simple heuristics that make us smart. London, England: Oxford University Press.

Gopher, D. (1996). Attention control: Explorations of the work of an executive controller. Cognitive Brain Research, 5, 23-38.

Gopher, D., Weil, M., \& Siegel, D. (1989). Practice under varying priorities: An approach to the training of complex skills. Acta Psychologica, 71, 147-177.

Hardy, D., Mouloua, M., Dwivedi, C., \& Parasuraman, R. (1995). Monitoring of automation failures by young and older adults. In Proceedings of the International Symposium on Aviation Psychology (pp. 1382-1386). Columbus, OH: Association of Aviation Psychology.

Hoffman, J. E., \& Subramaniam, B. (1995). The role of visual attention in saccadic eye movements. Perception and Psychophysics, 57, 787-795.

Hurst, K., \& Hurst, L. (1982). Pilot error: The human factors. New York, NY: Aronson.

Kahnemann, D., Slovic, P., \& Tversky, A. (1982). Judgement under uncertainty: Heuristics and biases. New York, NY: Cambridge University Press.

Karau, S. J., \& Williams, K. D. (1993). Social-loafing: A metaanalytic review and theoretical integration. Journal of Personality and Social Psychology, 65, 681-706.

Koshland, D. E. (1989). Low probability-high consequence accidents. Science, 244, 405.

Langer, E. J. (1982, April). Automated lives. Psychology Today, pp. $60-71$.

Langer, E. J. (1989). Mindfulness. Reading, MA: Addison-Wesley.

Layton, C., Smith, P. J., \& McCoy, C. E. (1994). Design of cooperative problem-solving system for en-route flight planning: an empirical evaluation. Human Factors, 36, 94-119.

Lee, J. D., \& Moray, N. (1992). Trust, control strategies and allocation of function in human-machine systems. Ergonomics, 35, $1243-1270$.

Lee, J. D., \& Moray, N. (1994). Trust, self-confidence, and operators' adaptation to automation. International Journal of Human-Computer Studies, 40, 153-184.

Lee, J. D., \& See, J. (2004). Trust in automation and technology: Designing for appropriate reliance. Human Factors, 46, 50-80.

Lee, J. D., \& Seppelt, B. D. (2009). Human factors in automation design. In S. Nof (Ed.), Springer handbook of automation (pp. 417-436). New York, NY: Springer.

Locke, E. A., \& Latham, G. P. (1990). A theory of goal setting and task performance. Englewood Cliffs, NJ: Prentice Hall.

Lorenz, B., Di Nocera, F., Rottger, S., \& Parasuraman, R. (2002). Automated fault-management in a simulated spaceflight micro-world. Aviation, Space, and Environmental Medicine, 73, 886-897.

Luedtke, A., \& Moebus, C. (2005). A case study for using a cognitive model of learned carelessness in cognitive engineering. In G. Salvendy (Ed.), Proceedings of the 11th International Conference of Human-Computer Interaction. Mahwah, NJ: Erlbaum. Retrieved from http://www.lks.uni-oldenburg .de/download/abteilung/Luedtke_Moebus_crv.pdf

Mack, A., \& Rock, I. (1998). Inattentional blindness. Cambridge, MA: MIT Press.

Madhavan, P., Wiegmann, D. A., \& Lacson, F. C. (2006). Automation failures on tasks easily performed by operators undermine trust in automated aids. Human Factors, 48, 241-256. 
Manzey, D., \& Bahner, J. E. (2005). Vertrauen in Automation als Aspekt der Verlaesslichkeit von Mensch-Maschine-Systemen [Trust in automation as an aspect of dependability of humanmachine-systems]. In K. Karrer, B. Gauss, \& C. Steffens (Eds.), Mensch-Maschine-Systemtechnik aus Forschung und Praxis (pp. 93-109). Duesseldorf, Germany: Symposion.

Manzey, D., Bleil, M., Bahner-Heyne, J. E., Klostermann, A., Onnasch, L., Reichenbach, J., \& Röttger, S. (2008). AutoCAMS 2.0 manual. Berlin, Germany: Berlin Institute of Technology, Chair of Work, Engineering and Organisational Psychology. Retrieved from http://www.aio.tu-berlin.de/?id=30492

Manzey, D., Reichenbach, J., \& Onnasch, L. (2008). Performanceconsequences of automated aids in supervisory control: The impact of function allocation. In Proceedings of the 52nd Meeting of the Human Factors and Ergonomics Society (pp. 297-301). Santa Monica, CA: Human Factors and Ergonomics Society.

Manzey, D., Reichenbach, J., \& Onnasch, L. (2009). Human performance consequences of automated decision aids in states of fatigue. In Proceedings of the 53rd Meeting of the Human Factors and Ergonomics Society (pp. 329-333). Santa Monica, CA: Human Factors and Ergonomics Society.

May, P., Molloy, R., \& Parasuraman, R. (1983, October). Effects of automation reliability and failure rate on monitoring performance in a multi-task environment. Paper presented at the annual meeting of the Human Factors Society, Santa Monica, CA.

McGuirl, J. M., \& Sarter, N. B. (2006). Supporting trust calibration and the effective use of decision aids by presenting dynamic system confidence information. Human Factors, 48, 656-665.

McKibbon, K. A., \& Fridsma, D. B. (2006). Effectiveness of clinicalselected electronic information resources for answering primary care physician's information needs. Journal of the American Medical Informatics Association, 13, 653-659.

Merlo, J. L., Wickens, C., \& Yeh, M. (2000). Effect of reliability on cue effectiveness and display signaling. In Proceedings of the 4th Annual Army Federated Laboratory Symposium (pp. 27-31). College Park, MD: Army Research Laboratory.

Merritt, S. M., \& Ilgen, D. R. (2008). Not all trust is created equal: Dispositional and history-based trust in human-automation interactions. Human Factors, 50, 194-210.

Metzger, U., Duley, J., Abbas, R., \& Parasuraman, R. (2000). Effects of variable-priority training on automation-related complacency: Performance and eye movements. In Proceedings of the IEA 2000/HFES 2000 Congress (pp. 2-346-2-349). Santa Monica, CA: Human Factors and Ergonomics Society.

Metzger, U., \& Parasuraman, R. (2001). The role of the air traffic controller in future air traffic management: An empirical study of active control versus passive monitoring. Human Factors, $43,519-528$.

Metzger, U., \& Parasuraman, R. (2005). Automation in future air traffic management: Effects of decision aid reliability on controller performance and mental workload. Human Factors, 47, 35-49.

Molloy, R., \& Parasuraman, R. (1996). Monitoring an automated system for a single failure: Vigilance and task complexity effects. Human Factors, 38, 311-322.

Moray, N. (1984). Attention to dynamic visual displays in manmachine systems. In R. Parasuraman \& D. R. Davies (Eds.), Varieties of attention (pp. 485-513). San Diego, CA: Academic Press.

Moray, N. (2003). Monitoring, complacency, scepticism and eutactic behaviour. International Journal of Industrial Ergonomics, 31, 175-178.

Moray, N., \& Inagaki, T. (2000). Attention and complacency. Theoretical Issues in Ergonomics Science, 1, 354-365.
Mosier, K. L. (2002). Automation and cognition: Maintaining coherence in the electronic cockpit. In E. Salas (Ed.), Advances in human performance and cognitive engineering research (Vol. 2, pp. 93-121). Amsterdam, Netherlands: Elsevier Science.

Mosier, K. L., Palmer, E. A., \& Degani, A. (1992). Electronic checklists: Implications for decision making. In Proceedings of the Human Factors Society 36th Annual Meeting (pp. 7-11). Santa Monica, CA: Human Factors and Ergonomics Society.

Mosier, K. L., \& Skitka, L. J. (1996). Human decision makers and automated decision aids: Made for each other? In R. Parasuraman \& M. Mouloua (Eds.), Automation and human performance: Theory and application (pp. 201-220). Mahwah, NJ: Erlbaum.

Mosier, K. L., Skitka, L. J., Dunbar, M., \& McDonnell, L. (2001). Aircrews and automation bias: The advantages of teamwork? International Journal of Aviation Psychology, 11, 1-14.

Mosier, K. L., Skitka, L. J., Heers, S., \& Burdick, M. (1998). Automation bias: Decision-making and performance in hightech cockpits. International Journal of Aviation Psychology, 8 , $47-63$.

National Transportation Safety Board. (1997). Grounding of the Panamanian passenger ship Royal Majesty on Rose and Crown shoal near Nantucket, Massachusetts, June 10, 1995 (Report NTSB/MAR-97-01). Washington, DC: Author.

Parasuraman, R. (2000). Designing automation for human use: Empirical studies and quantitative models. Ergonomics, 43, 931-951.

Parasuraman, R., Cosenzo, K., \& de Visser, E. (2009). Adaptive automation for human supervision of multiple uninhabited vehicles: Effects on change detection, situation awareness, and mental workload. Military Psychology, 21, 270-297.

Parasuraman, R., Molloy, R., \& Singh, I. L. (1993). Performance consequences of automation-induced "complacency." International Journal of Aviation Psychology, 3, 1-23.

Parasuraman, R., Mouloua, M., \& Molloy, R. (1996). Effects of adaptive task allocation on monitoring of automated systems. Human Factors, 38, 665-679.

Parasuraman, R., \& Riley, V. (1997). Humans and automation: Use, misuse, disuse, abuse. Human Factors, 39, 230-253.

Parasuraman, R., Sheridan, T. B., \& Wickens, C. D. (2000). A model for types and levels of human interaction with automation. IEEE Transactions on Systems, Man, and Cybernetics, Part A: Systems and Humans, 30, 286-297.

Parasuraman, R., Sheridan, T. B., \& Wickens, C. D. (2008). Situation awareness, mental workload, and trust in automation: Viable, empirically supported cognitive engineering constructs. Journal of Cognitive Engineering and Decision Making, 2, 141-161.

Parasuraman, R., \& Wickens, C. D. (2008). Humans: Still vital after all these years of automation. Human Factors, 50, 511-520.

Parasuraman, S., Singh, I. L., Molloy, R., \& Parasuraman, R. (1992). Automation-related complacency: A source of vulnerability in contemporary organizations. In R. Aiken (Ed.), Education and society: Information processing 92 (Vol. 2, pp. 426-432). Amsterdam, Netherlands: Elsevier Science.

Prinzel, L. J. (2002). The relationship of self-efficacy and complacency in pilot-automation interaction (Technical Memorandum No. TM-2002-211925). Hampton, VA: National Aeronautics and Space Administration Langley Research Center.

Prinzel, L. J., De Vries, H., Freeman, F. G., \& Mikulka, P. (2001). Examination of automation-induced complacency and individual difference variates (Technical Memorandum No. TM-2001-211413). Hampton, VA: National Aeronautics and Space Administration Langley Research Center. 
Rasmussen, J. (1986). Information processing and human-computer interaction. Amsterdam, Netherlands: North Holland.

Reichenbach, J., Onnasch, L., \& Manzey, D. (in press). Misuse of automation: The impact of system experience on complacency and automation bias in interaction with automated aids. In Proceedings of the 54th Meeting of the Human Factors and Ergonomics Society. Santa Monica, CA: Human Factors and Ergonomics Society.

Rovira, E., McGarry, K., \& Parasuraman, R. (2007). Effects of imperfect automation on decision making in a simulated command and control task. Human Factors, 49, 76-87.

Sarter, N. B., \& Schroeder, B. (2001). Supporting decision making and action selection under time pressure and uncertainty: The case of in-flight icing. Human Factors, 43, 573-583.

Senders, J. W. (1964). The human operator as a monitor and controllers of multidegree of freedom systems. IEEE Transactions on Human Factors in Electronics, HFE-5, 1-6.

Shepherd, M., Findlay, J. M., \& Hockey, R. J. (1986). The relationship between eye movements and spatial attention. Quarterly Journal of Experimental Psychology A, 38, 475-491.

Sheridan, T. B. (1970). On how often the supervisor should sample. IEEE Transactions on Systems Science and Cybernetics, SSC6(2), 140-145.

Sheridan, T. B. (2002). Humans and automation: Systems design and research issues. Santa Monica, CA: Human Factors and Ergonomics Society.

Sheridan, T. B., \& Verplank, W. L. (1978). Human and computer control of undersea teleoperators (Technical Report, ManMachine Systems Laboratory, Department of Mechanical Engineering). Cambridge, MA: MIT.

Simons, D. J., \& Rensink, R. A. (2005). Change blindness: Past, present, and future. Trends in Cognitive Sciences, 9, 16-20.

Singh, I. L., Molloy, R., Mouloua, M., Deaton, J., \& Parasuraman, R. (1998). Cognitive ergonomics of cockpit automation. In I. L. Singh \& R. Parasuraman (Eds.), Human cognition: A multidisciplinary perspective (pp. 242-253). New Delhi, India: Sage.

Singh, I. L., Molloy, R., \& Parasuraman, R. (1993a). Automationinduced "complacency": Development of the complacencypotential rating scale. International Journal of Aviation Psychology, 3, 111-121.

Singh, I. L., Molloy, R., \& Parasuraman, R. (1993b). Individual differences in monitoring failures of automation. Journal of General Psychology, 120, 357-373.

Singh, I. L., Molloy, R., \& Parasuraman, R. (1997). Automationrelated monitoring inefficiency: The role of display location. International Journal of Human-Computer Studies, 46, 17-30.

Singh, I. L., Sharma, H. O., \& Parasuraman, R. (2001). Effects of manual training and automation reliability on automation induced complacency in a flight simulation task. Psychological Studies, 46, 21-27.

Skitka, L. J., Mosier, K. L., \& Burdick, M. (1999). Does automation bias decision-making? International Journal of HumanComputer Studies, 51, 991-1006.

Skitka, L. J., Mosier, K. L., \& Burdick, M. (2000). Accountability and automation bias. International Journal of Human-Computer Studies, 52, 701-717.

Skitka, L. J., Mosier, K. L., Burdick, M., \& Rosenblatt, B. (2000). Automation bias and errors: Are crews better than individuals? International Journal of Aviation Psychology, 10, 85-97.

St. John, M., Smallman, H. S., Manes, D. I., Feher, B. A., \& Morrison, J. G. (2005). Heuristic automation for decluttering tactical displays. Human Factors, 47, 509-525.
Szalma, J. (2009). Incorporating human variation into human factors/ ergonomics research and practice [Special issue]. Theoretical Issues in Ergonomics, 10, 377-488.

Taylor, P. M., Champness, J., Given-Wilson, R. M., Potts, H. W. E., \& Johnston, K. (2004). An evaluation of the impact of computer-based prompts on screen readers' interpretation of mammograms. British Journal of Radiology, 77, 21-27.

Thackray, R. I. (1981). The stress of boredom and monotony: A consideration of the evidence. Psychosomatic Medicine, 43, 165-176.

Thackray, R. I., \& Touchstone, R. M. (1989). Detection efficiency on an air traffic control monitoring task with and without computer aiding. Aviation, Space, and Environmental Medicine, 60, 744-748.

Thomas, L., \& Wickens, C. D. (2006). Effects of battlefield display frames of reference on navigation tasks, spatial judgments, and change detection. Ergonomics, 49, 1154-1173.

Tsai, T. L., Fridsma, D. B., \& Gatti, G. (2003). Computer decision support as a source of interpretation error: the case of electrocardiograms. Journal of the American Medical Informatics Association, 10, 478-483.

Tversky, A., \& Kahneman, D. (1974). Judgement under uncertainty: Heuristics and biases. Science, 185, 1124-1131.

Vincenzi, D. A., Muldoon, R., Mouloua, M., Parasuraman, R., \& Molloy, R. (1996). Effects of aging and workload on monitoring of automation failures. In Proceedings of the 40th Annual Meeting of the Human Factors and Ergonomics Society (pp. 1556-1561). Santa Monica, CA: Human Factors and Ergonomics Society.

Westbrook, J. I., Coiera, W. E., \& Gosling, A. S. (2005). Do online information retrieval systems help experienced clinicians answer clinical questions? Journal of the American Medical Informatics Association, 12, 315-321.

Wickens, C. D., \& Dixon, S. (2007). The benefits of imperfect diagnostic automation: A synthesis of the literature. Theoretical Issues in Ergonomics Science, 8, 201-212.

Wickens, C. D., Dixon, S., Goh, J., \& Hammer, B. (2005). Pilot dependence on imperfect diagnostic automation in simulated UAV flights: An attentional visual scanning analysis. In Proceedings of the 13th International Symposium on Aviation Psychology (pp. 919-923). Columbus, OH: Association of Aviation Psychology.

Wickens, C. D., Gempler, K., \& Morphew, M. E. (2000). Workload and reliability of traffic displays in aircraft traffic avoidance. Transportation Human Factors Journal, 2, 99-126.

Wickens, C. D., \& Hollands, J. G. (2000). Engineering psychology and human performance. New York, NY: Prentice Hall.

Wickens, C. D., McCarley, J. S., Alexander, A., Thomas, L., Ambinder, M., \& Zheng, S. (2007). Attention-situation awareness (A-SA) model of pilot error. In D. Foyle \& B. Hoeey (Eds.), Pilot performance models (pp. 213-240). Mahwah, NJ: Erlbaum.

Wiegmann, D. A. (2002). Agreeing with automated diagnostic aids: A study of users' concurrence strategies. Human Factors, 44, 44-50.

Wiener, E. L. (1981). Complacency: Is the term useful for air safety? In Proceedings of the 26th Corporate Aviation Safety Seminar (pp. 116-125). Denver, CO: Flight Safety Foundation

Wiener, E. L., \& Curry, R. E. (1980). Flight-deck automation: Promises and problems. Ergonomics, 23, 995-1011.

Woods, D. D. (1996). Decomposing automation: Apparent simplicity, real complexity. In R. Parasuraman \& M. Mouloua (Eds.), Automation and human performance (pp. 3-18). Mahwah, NJ: Erlbaum. 
Raja Parasuraman is a university professor of psychology at George Mason University. He obtained his $\mathrm{PhD}$ in applied psychology from Aston University in 1976.

Dietrich H. Manzey is a professor of work, engineering, and organizational psychology at the Institute of Psychology and Ergonomics, Berlin Institute of
Technology, Germany. He received his $\mathrm{PhD}$ in experimental psychology at the University of Kiel, Germany, in 1988 and his habilitation in psychology at the University of Marburg, Germany, in 1999.

Date received: December 1, 2009

Date accepted: May 21, 2010 